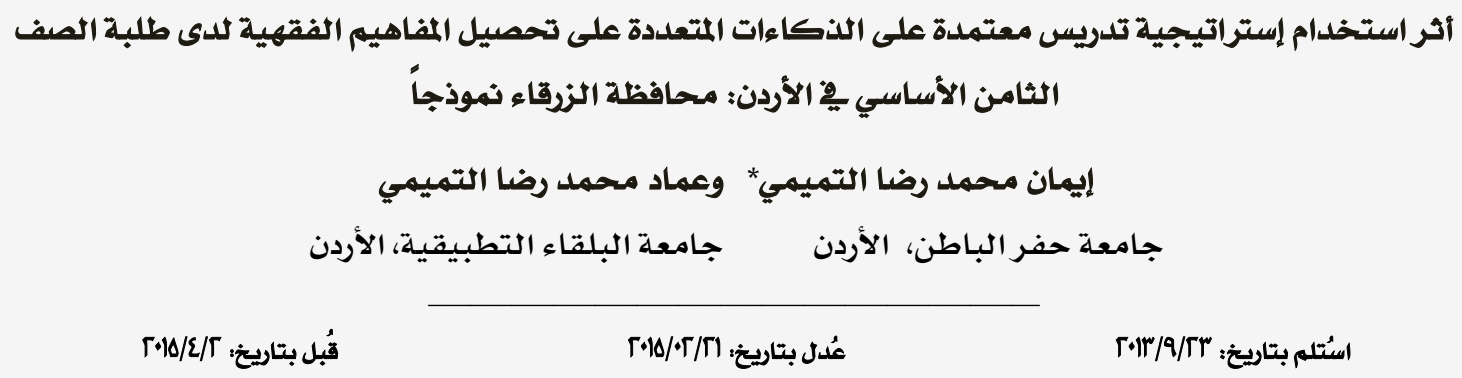

المستخلص: هدفت هذه الدراسة إلى الكشف عن أثر استخدام إستراتيجية تدريس مبنية على نظرية الذكاءات المتعددة ِوخ تحصيل

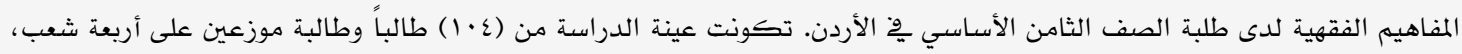
مجموعتان تجريبيتان درستا باستخدام إستراتيجية معتمدة على الذكاءات المتعددة، ومجموعتان ضابطتان درستا بالطريقة الاعتيادية.

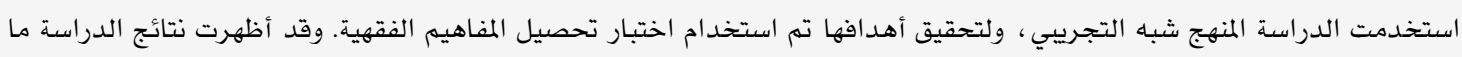

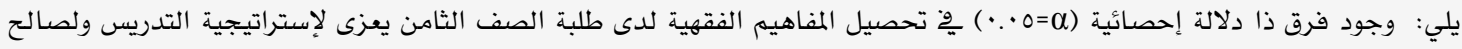

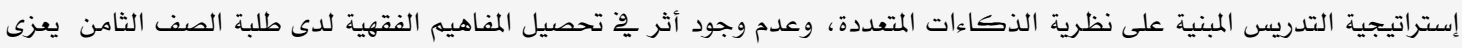
للتفاعل بين إستراتيجية التدريس المبنية على نظرية الذكاءات المتعددة والجنس. كلمات مفتاحية: إستراتيجية الذكاءات المتعددة، المفاهيم الفقهية ، التربية الإسـلامية.

\title{
The effect of Multiple Intelligences Theory-based Strategy on Achieving the Concepts of Jurisprudence among 8th Grade Students
}

Eman R. Al Tamimi*

Hafr Al Baten University, Jordan
\& Imad R. Al Tamimi

Al Balqa Applied University, Jordan

\begin{abstract}
This study investigated the effect of using a teaching strategy that is based on multiple intelligences theory (MIT) on achieving the concepts of Jurisprudence among 8th grade students. The study's sample consisted of 104 students divided into four groups: two experimental groups taught by using a teaching strategy that was based on multiple intelligences theory (MIT); and two control groups examined in the traditional method. To achieve the objectives of the study, an achievement test was used. The results of the study showed a statistically significant difference at $(\alpha=0.05)$ on achieving jurisprudence concepts among 8th grade students that may be attributed to using a teaching strategy based on MIT. There was no effect for the interaction between teaching strategy and student's gender on achieving Jurisprudence concepts among 8th grade students.
\end{abstract}

Keywords: Teaching strategy based on multiple intelligences, jurisprudence concepts, Islamic education.

*dr.emantamimi@yahoo.om 
ذلك يعد أساساً لخلق بيئة تعليمية تتيح الفرص

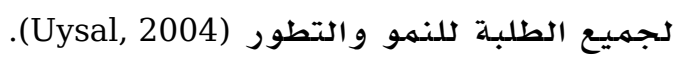
ظل هذا الهفهوم التقليدي للذكاء سائداً لأوقـات

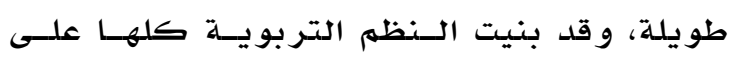

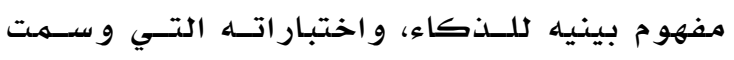

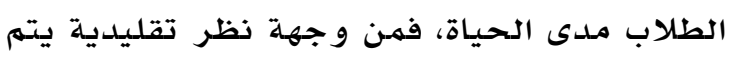
تعليهم جميع الطلبة بالطريقة نفسها دون اعتبـار

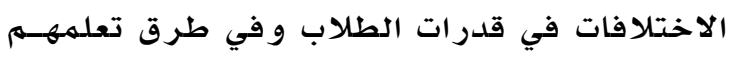

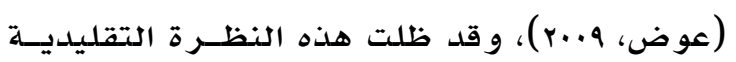

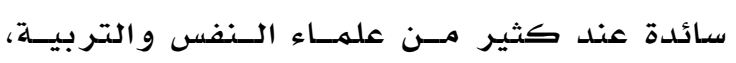

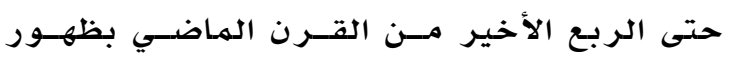
نظرية الذكاءات المتعددة.

لقد تم تطوير نظرية الذكاءات المتعددة في

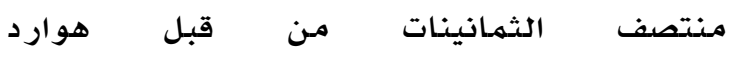

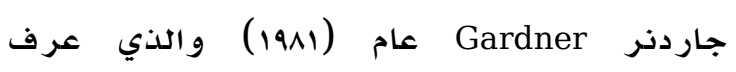
الذكاء بأنه القدرة على حل المشكلات، و إبداع

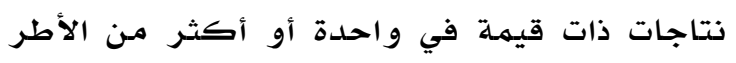

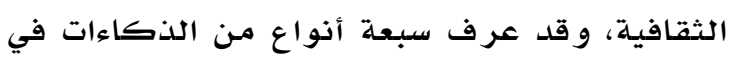

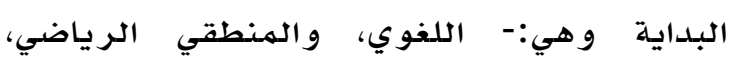

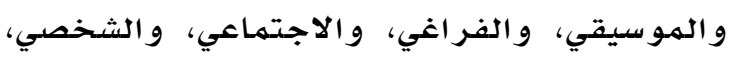

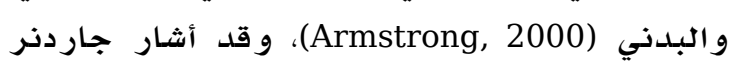

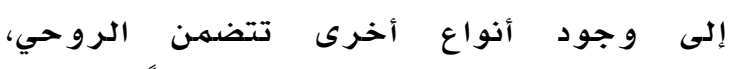

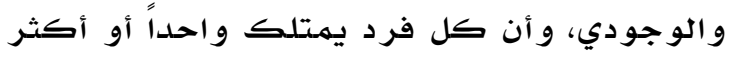

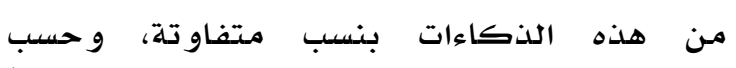
نظريته فإن هنالك طرائق كثيرة لتكون ذأكياً

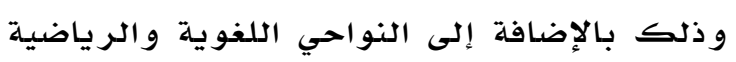

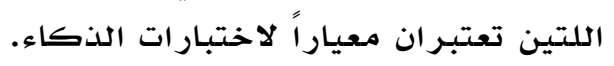
لقد كانت معظم بحوث ونظريات الذكاء تنظر إلى الذكاء على أنه يجب أن يفسر من النه المنظور

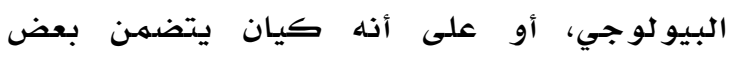

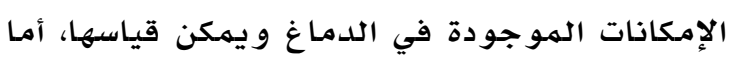

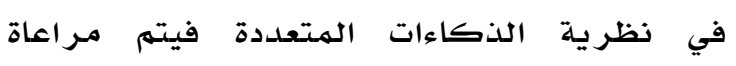
السياق الذي يعيث فيه الفرد والقيهم السائدة في النياء

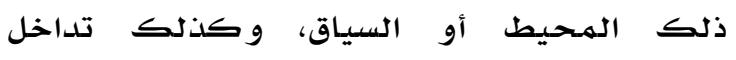

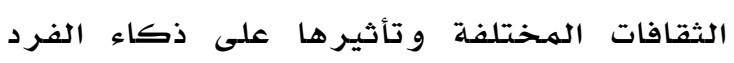

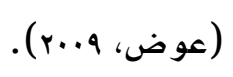

إن التحديات التي تفرضها التغيــرات المتســارعة

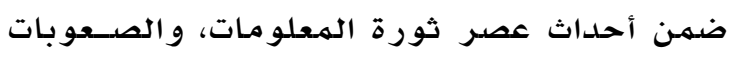

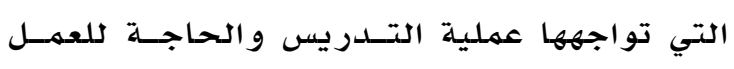

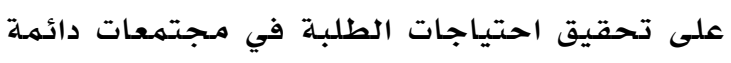

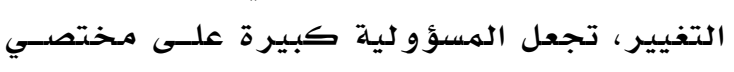

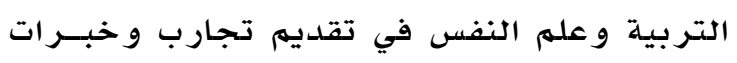

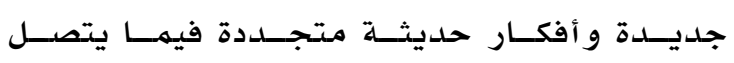

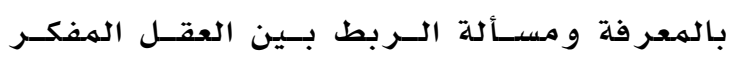

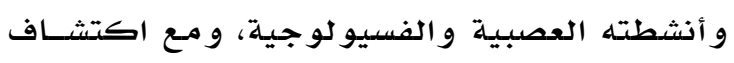

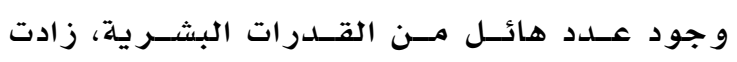

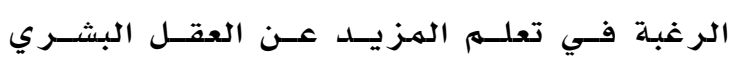

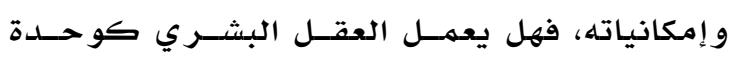

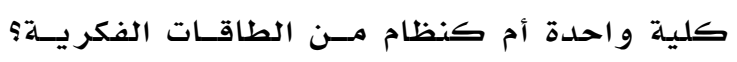

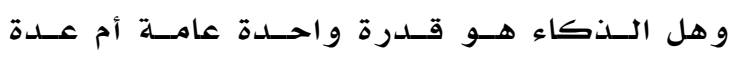

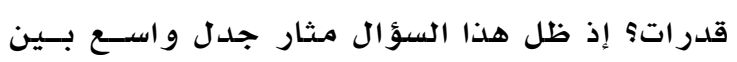

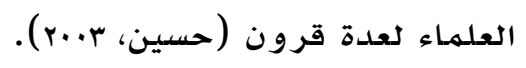

كان الاعتقاد السائد عند الكثير مـن علماء النفس

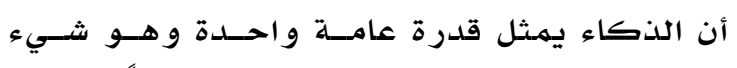

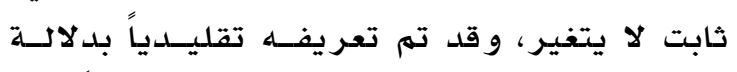

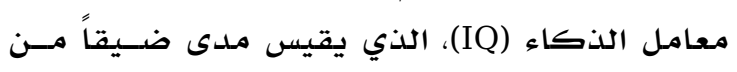

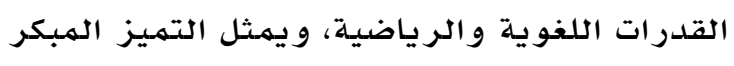

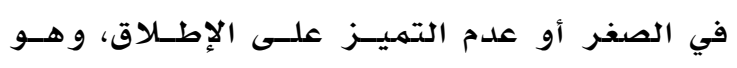

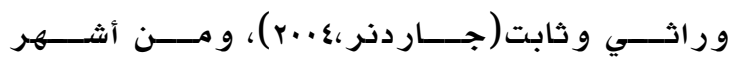

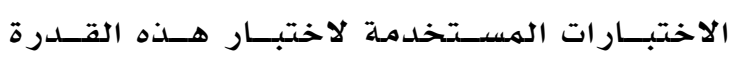

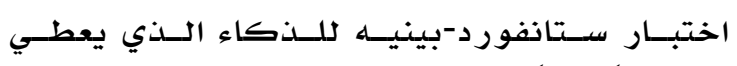

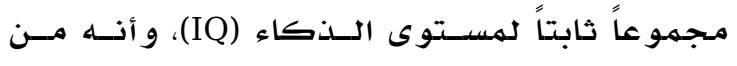

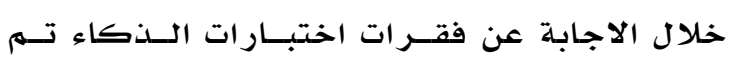
الاعتقاد أن الذكاء هو قدرة عامـة يمكـن قياسـها

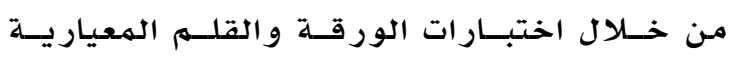

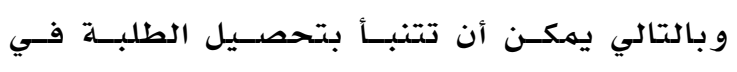
المددرسة (Bilgin, 2006).

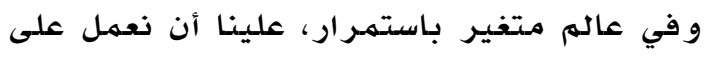

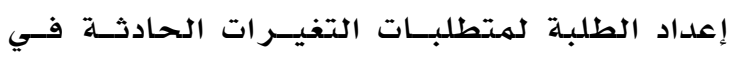

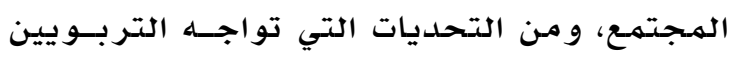

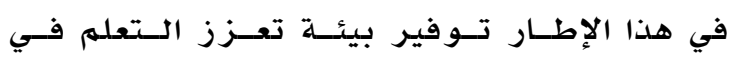

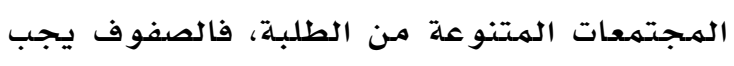

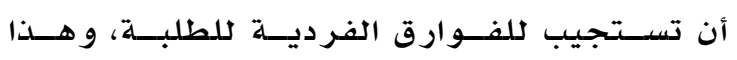
يتطلب مـن التربـويـين إعـادة التفكيـر وتعـديل مفاهيههم حول ذكاءات الطلبــة و مــواهبهـه ؛ لأن 
أو كتابة الشعر، أو التمثيل، ويتضمن هذا

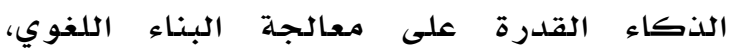
و الصوتيات، و المعاني، وفهم قواعد اللغة كالنحو

و معاني الكلمات، و إقناع شخص ولعمل ولهمل شيء ما.

نانيا :- الذكاء المنطقي الرياضي -Logical) Mathematical Intelligence) استخدام الأرقام بكفاءة الرياضي،

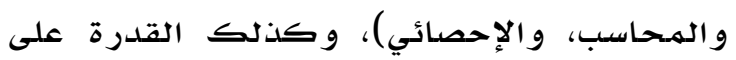

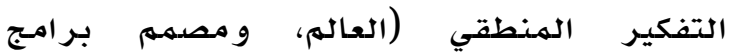

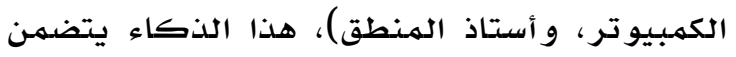

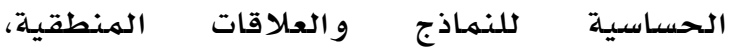

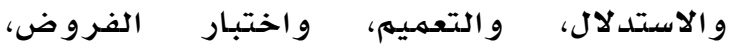
و المعالجات الحسابية.

ثالثا :- الذكاء المكاني/البصري Spatial Visual) و يتضهن القدرة على إدراك العالم Intelligence)

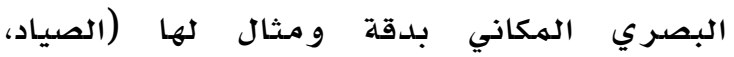
والدليل، والكشاف)، ووهي تتضهن أيضاً القدرة على التصور البصري و وتمثيل الأفكار ذات التهيل الطبيعة البصرية أو المكانية والحساسية تجاه

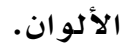

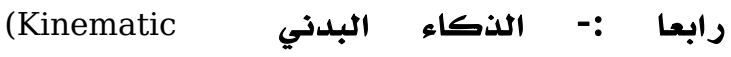
يعرف جاردنر الذكاء البدني على Intelligence) أنه القدرة على التحكم في حركة أجزاء الجسم

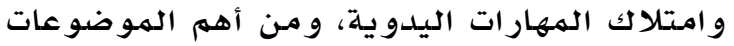

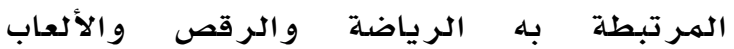
الجسمية و التمـرينات الرياضية.

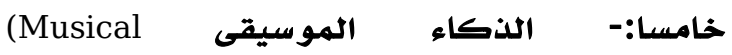
و هو القدرة على إدرالك الموسيقى Intelligence)

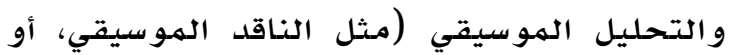
الهؤلف الموسيقي) و التعبير الهموسيقي (مثل الهيل

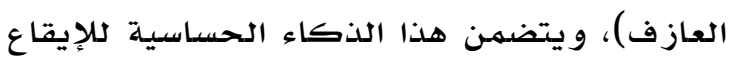
و النغمهة.

سادسا:- الذكاء الشخصي الداخلي مهي (Intraو وهو معرفة الذئة personal Intelligence) والقدرة على التصرف المتوائم مـع هذه المعرفة، ويتضمن ذلك أن تكون لديك صورة دقيقة عن

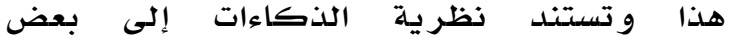

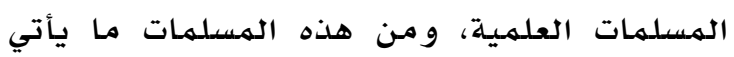

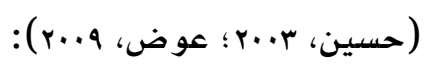

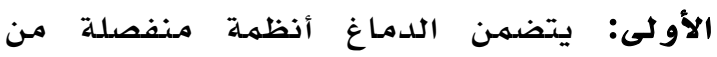

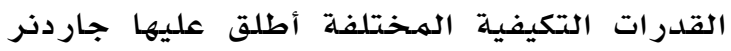

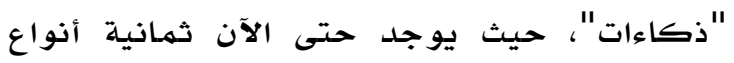

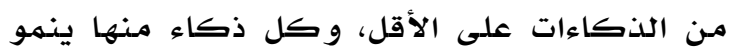

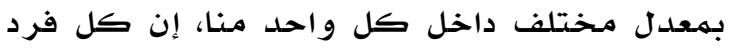
يمتلك و احداً أو أكثر مـن هذه الذكاءات ورلكن ولكن بلدر جات متفاو تلة.

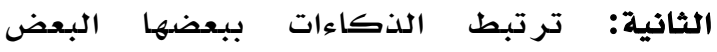

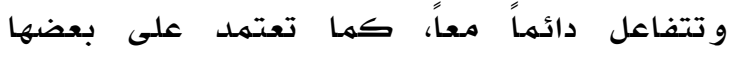
البعض إذا ما دعت الحاجة إلى ذلك، و لا يمكن ملهن

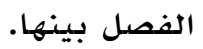

الثالثة: وتتضمن أن كل فرد يمتلك عددا من الذكاءات، و تتوقف المستويات الفردية للكفاءة في كل واحدة من هذه الذكاءات على كل من

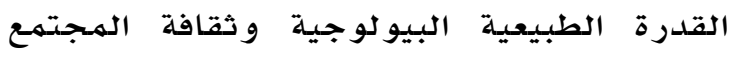
الذي يعيش فيه الفرد و أساليب تربيته. و قد أوجدت نظريسـة الـذكاءات المتعـددة آفاقـاً

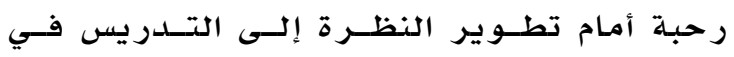

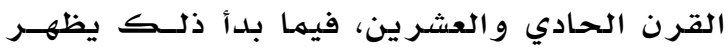

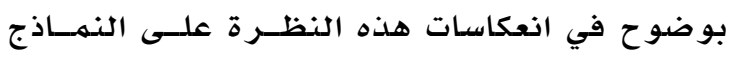

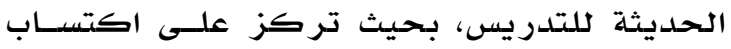
المتعلهم للمعرفة، في نفس الوقت الذي توفيه فر فيدر فيه إرشادات للمعلهم حول كيفيسة تصـهميهم نشـاطات

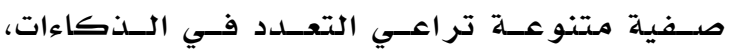

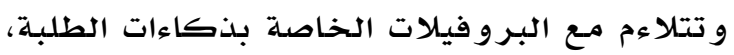

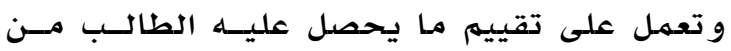
معر فة بطر يقة مناسبة (Hoerr, 2000). (Gardner, 1998) جار دنر يشير

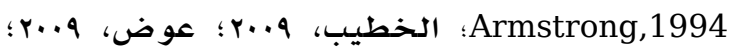
(Hernández,et.al 2010

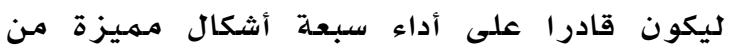
الذكاءات و هي: - تلذون

اولا :- الذكاء اللغوي اللفظي الماء (Linguistic) و يتهثل في القدرة على استخدام Intelligence) الكلمهات بكفاءة شفهياً، كما في رواية الحكايات، 
و مـراعاة الذكاءات المتعددة للطلاب لجعل المواد

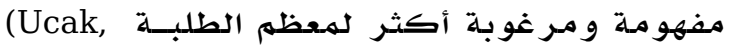
. 2006)

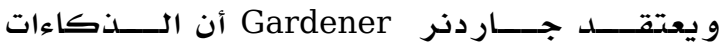

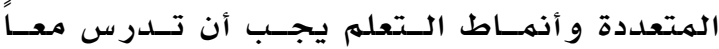
و ليس بشكل منفصل، و بذلك يمكن للمعلمين أن

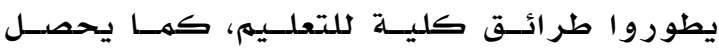
الطلبة على تعلم أفضل عندما يتعر ضون لأنماط تعليم متعددة، لذا فإن المعلهم يجب عليه استخدام الذكاءات المتعددة في الدروس لأن ذلك يساهم في إعداد الطلبة للخبرات الحقيقية فـي الحيـاة ليصبـحوا أعضداء منتتجين في الهـجتمـع، و يســاعد

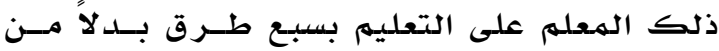

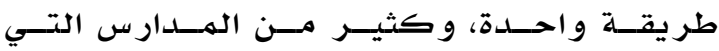
استخدمت هذه الذكاءات وجسـدت دافعيـة أكبـر

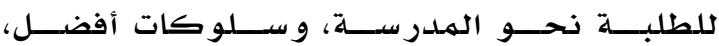
و تحصيلاً أعلى (Pociask, 2007).

إن وجود الاختلافات بين الطلبة يحتمر على

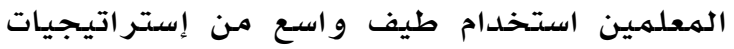

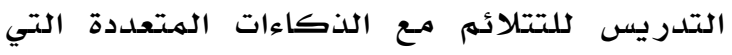

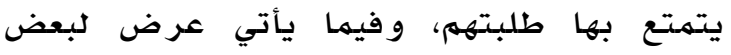

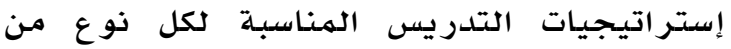

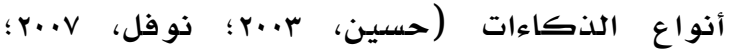

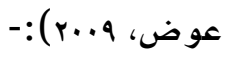

أولا: إستراتيجيات الذكاء اللغوي:- يعد الذكاء اللغوي من أسهل أنواع الذكاءات الذاء التي يمكن

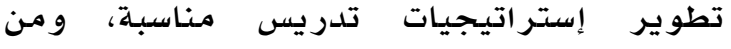
الإستراتيجيات المناسبة لتنمية الذكاء الذيراس اللغوي: العصف الذهني: هي إستر اتيجية ترى أن التفكير

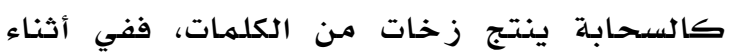
العصف الذهني ينتج الطلبة وابلا من الأفكار اللفظية، التي يتم جمعها على السبورة بحيث يتم التهم التها

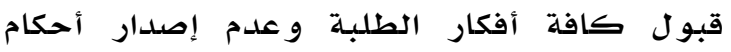
مسبقة، وفي نهاية جلسة العصف الذهني يتم مناقشة أفكار الطلبة وفق وفي معايير يتفق عليها

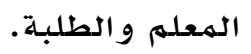

ثانيا: إستراتيجيات الذكاء الرياضي :- يغلب استخدام التفكير الناقد في مساقات الرياضيات

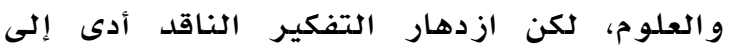

سابعا :- الذكاء الخخارجي الذقاء (Inter-personal وهو القدرة على إدراك الحالات Intelligence)

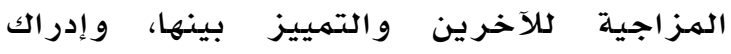
نواياهم ودو افعهم و مشاعر هم، كما يتضمن هذا الذكاء القدرة على الاستجابة المناسبة للعحلاقات الاجتماعية بصورة عملية بحيث تؤثر في توجيه

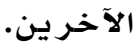

و هنالك العديد من الفوائد لنظرية الذكاءات المتعددة و والتي يتفق عليها التربويون، وقدل

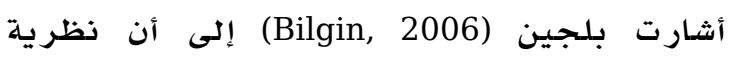

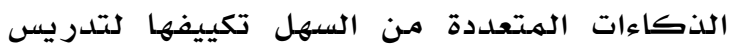

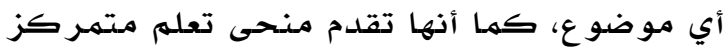

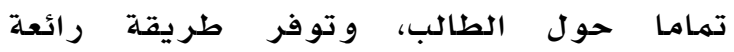
لاستخدام التعلهم التعاوني والتعلم ذو ذو النهاية

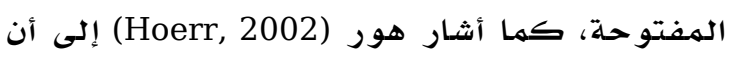
نظرية الذكاءات المتعددة تركز على نقطتين أساسيتين أولا: مزيد من الطلاب سوف يحققون

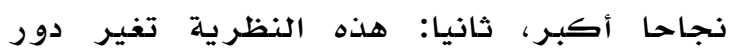

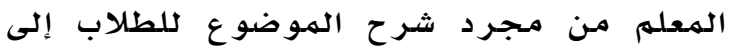

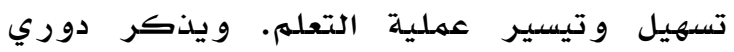
المشار إليه في بلجين (Bilgin, 2006) إلى أن أن

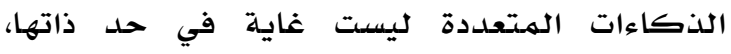
لكنها أداة قوية يمكن أن تساعدنا لبلوغ النهائات الغدايات

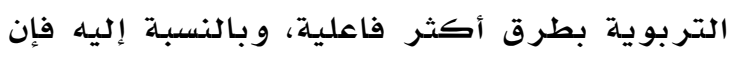
نظرية الذكاءات المتعددة يمكن أن تعتبر مفيدة إنهرة بشكل خاص لغايتين تربويتين هما:

• أنها تتيح لنا تخطيط البرامـ التربوية التي تمكن الطلبـة من تمييز الغايات التي يسعون إلى تحقيقها.

• أنها تمكن عددا أكبر من الطلاب أن يفهموا

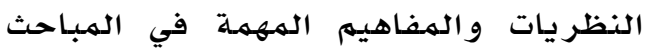
الدر اسية الهختلفة.

يقول جاردنرGardene: إن طلبــة الصـف ليسـوا

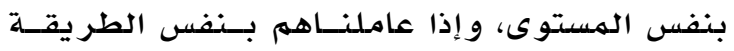

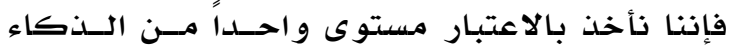
فقط، ومن ثم فإن المعلمين يجب أن لا يعتمــدوا

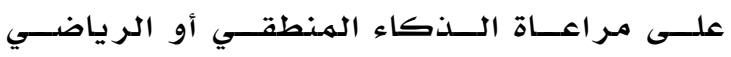

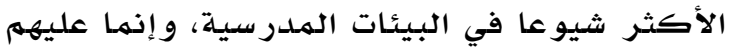

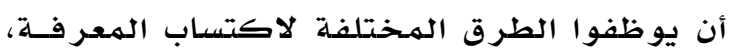


اليوم الهدرسي لهساعدة الطلبة الذين يتمتعون

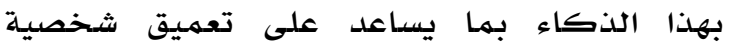

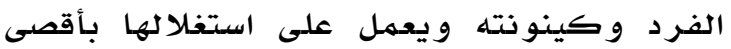

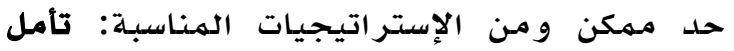
الدقيقة الواحلدة: أن يتيح المعلهم للطلبة أثناء الدرس وخاصلة عندما يتلقى الطالب مثيرا على

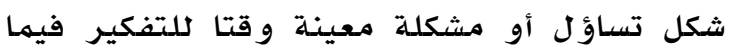
و صل إليه من مثير ات أو منبهات. إن الناظر المتأمل في الأدب التربوي يدرك جلياً أن تدريس التربية الاسلامية يعيث واقدياً مريراً

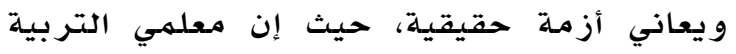

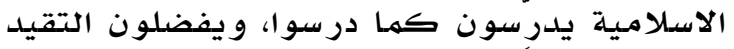

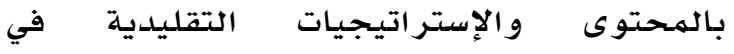

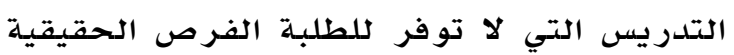

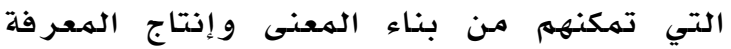

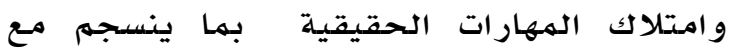
التنوع و في الخصائص والقدرات العقلية والتفضيلات التعلمية للطلبة، مـما يجعل التعلهم صمياً يخلو من المعنى، ولا يحقق فهم الطلبة

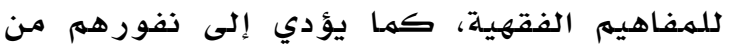

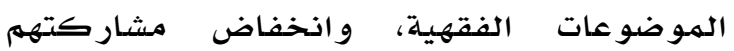
واستمتاعهم في حصص التربية الاسلامية، إن

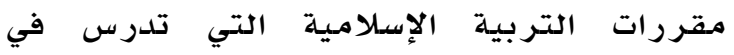

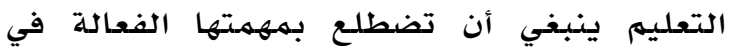
تحقيق أهداف التربية الإسلامية، وبخاصة الفقه الفه

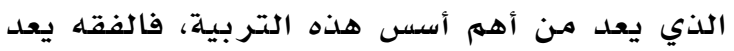
ثمرة ونتاجاً لجهود الفقهاء في بيان أحكام

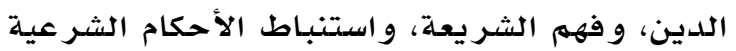

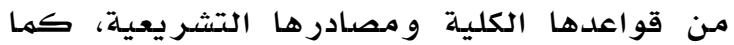
أنه يعنى بتعلهم الفرد أمور دينه ودنياه، و يعمل على تكييف سلوكه ووفق أحكام دينه قولاً و عملاً، وهذا يحتاج إلى الفهم السليه و التطبيق الصحيح

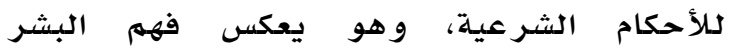

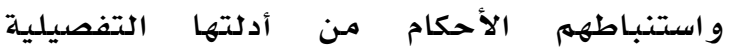

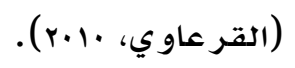

وقد أثبتت العديد مـن الدراسات فاعلية أنثطة

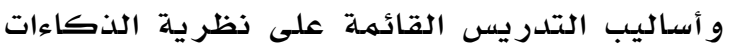
المتعددة في تحسين تحصيل الطلبة و منها دراسـة

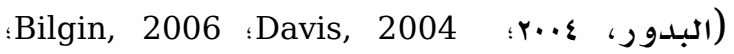

اقتراح طرق متعددة للتأثير في العلوم

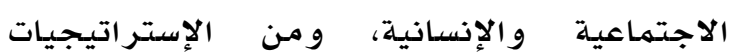

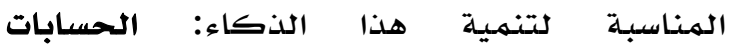
والكميات: لا يقتصر استخدام العمليات الحسـابية على الرياضيات و العلوم، حيث يمكن استخدامها في موضوعات مختلفة كالعلوم الاجتماعية عند حساب معدل النمو السكاني مثثلا. ثالثا: إستراتيجيات الذكاء المكاني:- يقوم على فكرة تمثيل المعلومات للطلبة من خلال أساليب مرئية متنوعة ومن الإستر اتيجيات الهـناسبـة لتطوير هذا الذكاء: التخيل البصري: وتقوم على ترجمـة الهوضوع إلى صدور ذهنيـة.

رابعا: إستراتيجيات الذكاء الحركي:- تنظر

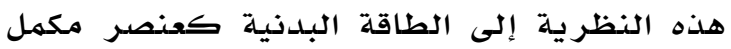
للذكاء الإنسـاني، و مـن الإستراتئجيات المناسبـة لتتمية هذا الذكاء: مسرح الصف: تتضمن أنشطة تعليمية تعلمية تتطلب من الطلاب تمثيلا حركيا للنصوص و المشكلات التي يتعرضون لها منايه في محتوى المناهج الدراسية، مثلا يكلف الهعلدم أحد الطلبـة بلعب دور البطل صلاح الدين الأيوبي.

خامسا: إستراتيجيات الذكاء الموسيقي:- هناك عدد قليل من القطع الموسيقية التي ارتبطت بالهنهاج ومن الإستر اتيجيات المناسبة: الأغاني

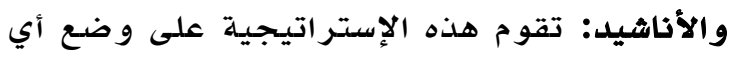
محتوى تعليهـي يرغب الهمعلم بتعليمـه للطلاب في صورة إيقاعية بحيث يمكن للطلبة غناءه

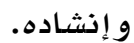

سادسا: الشختر الذيجي الخارجي:- تعتبر مهارة التواصل من المهارات

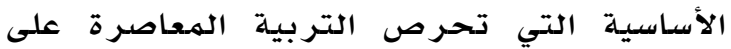

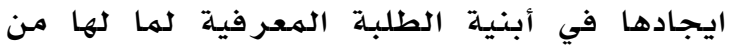
تأثير فعال في عملية التعليهم والتعلهم ومن لهن الإستر اتيجيات الهناسبة: المجموعات التعاونية:

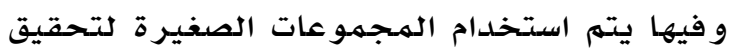
أهداف تعليمية مشتر كة. سابعا: إستراتيجيات الذكاء الشخصي الداخلي:على المعلم أن يوفر فرصاء صثيرة في أثناء 


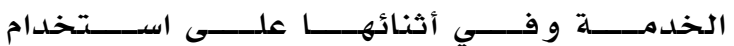

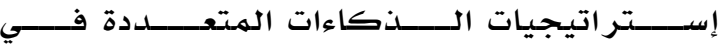

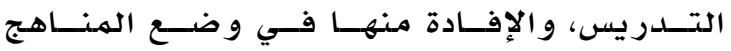

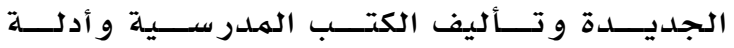

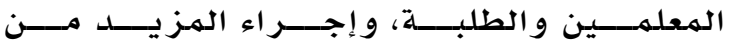

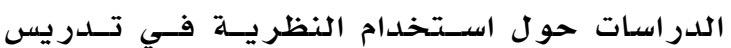
المواضيع العلمية.

قامت ديفس (Davis, 2004) بدراسـة هدفت إلى

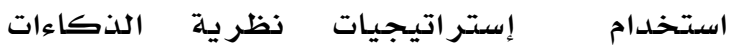
المتعددة لزيادة التحصيل العلهمي لطلبـة الصف

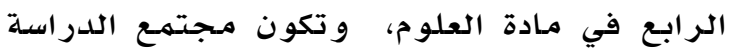

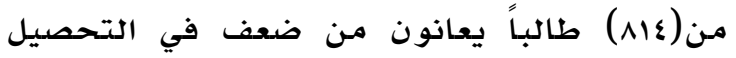

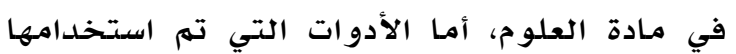
فهي تختلف حسب المخرج (التقارير الربعية،

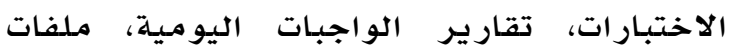

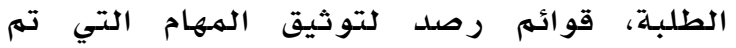

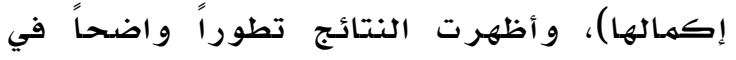
تحصيل الطلبة، ووفي تصرفاتهم، ووفي احترامهمه لأنفسهم، وعليه أوصت الدراسة بإعطاء الطلبة الطبة

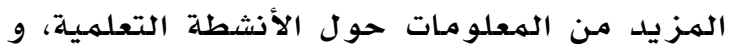

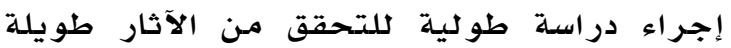

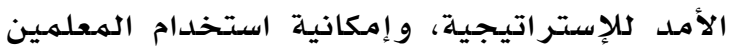

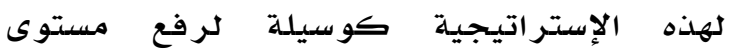
التحصيل الاكاديهي للطالب، وتعزيز تنمية قدر اتهم الههنية. و في در اسـة لسبلغين (Bilgin, 2006) و التي هدفت بشكل أسـاسـي إلـى الهقارنــة بــين أثـر تطبيـق

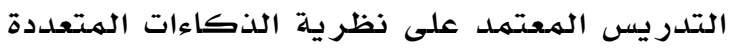
وبين الطرق التقليدية في تــدريس العلــوم علـى الـى

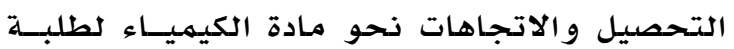

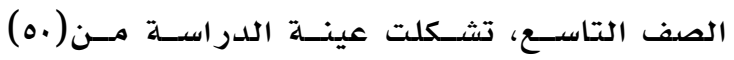
طالب موزعين على شعبتين (ro) تجر يبية و (ro)

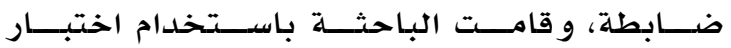
تحصيلي، وومقياس اتجاهات نحو الكيمياء، أظهرت

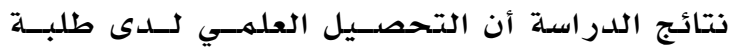

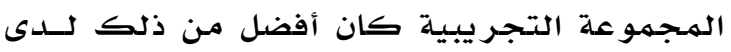

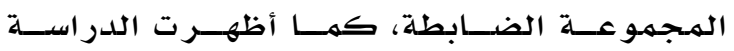
فروقات جوهرية في اتجاهات الطلبــة التـي تـم

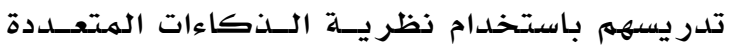
مقار نــة باتجاهـات طلبــة الهـجمهو عــة الضــابطة

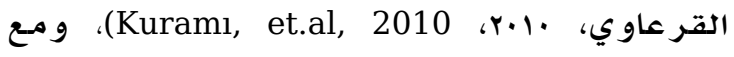

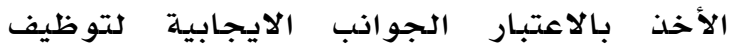
النظرية في عملية التعله، لخلق بيئة تعلمية

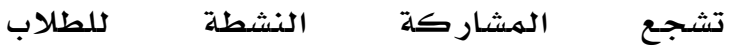
.(Davis, 2004)

و يضاف إلى ذلك ما لاحظه أحد الباحثين أثناء عملها كمدرسة في وزارة التربية والتعليم من

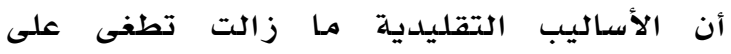

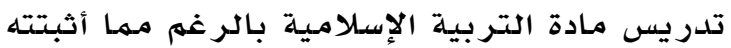
الدراسـات من فعالية استخدام مثل هذه النظريات في التدريس؛ ربما لغياب معر فتهمه بهذه النظرية، وقد تبنت وزارة التربية و التعليم إستر اتيجيات

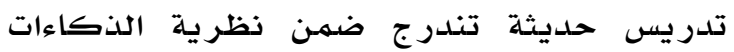
المتعددة، ومن هنا جاءت فكرة هذه الدراسلة للبحث في أثر استخدام إستراتيجية تلدريس مبنية على نظرية الذكاءات المتعددة في مبحث الذي

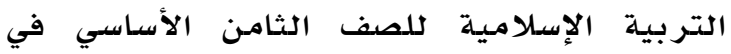

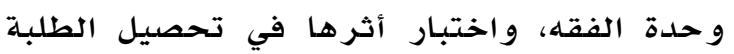
للمففاهيم الفقهية. و قد أجريـت العديـــ مــن الدراســات والبحــوث

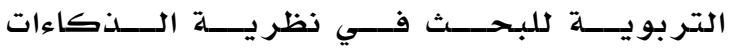

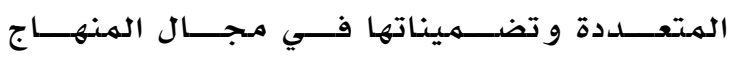

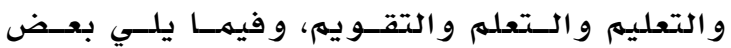

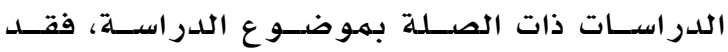

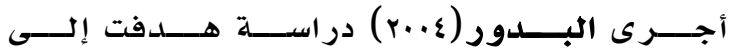

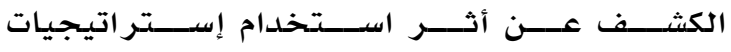

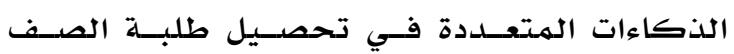

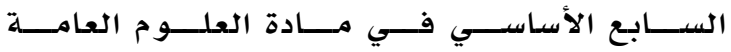

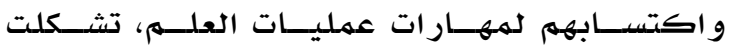
عينــة الدر اســة مـن (90) طالبــاً وطالبــة، ووقــام الباحسث باسـتخدام اختبــار تحصـيلي فـي مــادة

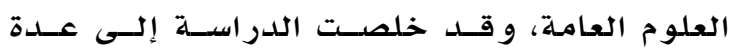

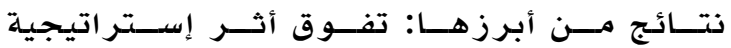

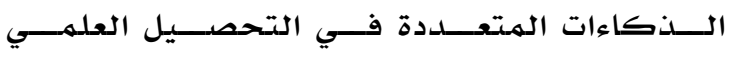

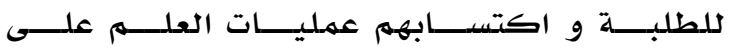

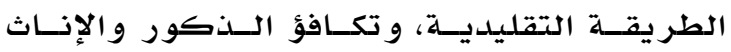

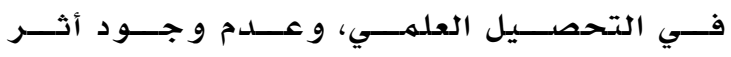

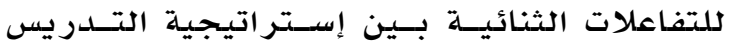

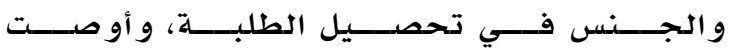
الدراسـة بضـرورة تــدريب معلهـي العلــوم قبـل 
تجريبية إناث، ضابطة ذكور، ضابطة إناث، و لتتفيذ هذه الدراسـة قامت الباحثة بـإعداد اختبار تحصيل المفاهيم الفيزيائية من نوع الاختيار من

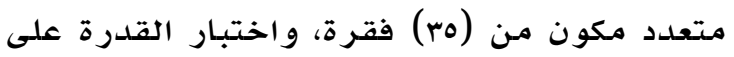
حل المشكلات ومقياس الاتجاهات العلمية، و أظهرت نتائج الدراسة ما يلي: وجود فرق ذي

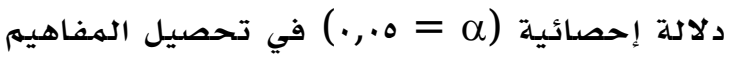

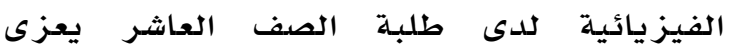

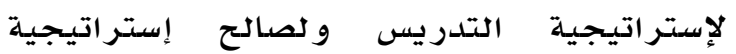
التدريس المبنية على نظرية الذكاءات المتعددة، عدم وجود أثر في تحصيل المفاهيم الفيزيائية لدى طلبة الصف العاشر يعزى للتفاعل بين

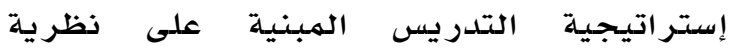
الذكاءات المتعددة والجنس، وجود فروق ذات دلالة إحصائية يعزى لاستخدام إستراتيجية التدريس المبنية على نظرية الذكاءات المتعددة

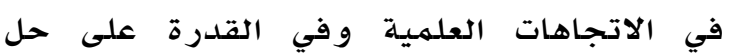
الهشكلات، و عدم وجود فروق ذات دلادلة إحصائية في الاتجاهات العلميلة والقدرة على حل المشكلات يعزى للتفاعل بين ايتراتيجية التدريس المبنية على نظرية الذكاءات الهتعددة و الجنس. كما قام القر عاوي (·r.r) بدر اسـة هدفت معر فة

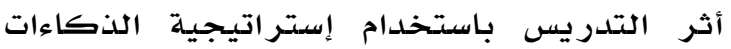

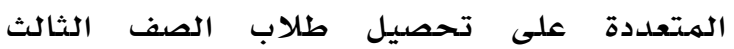
المتوسط في مقرر الفقه، تم استخدام المنهج

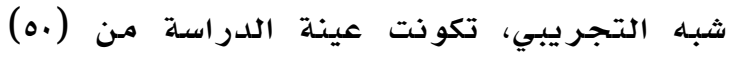
طالباً، موزعين على مجموعتين: تجريبية درية درست

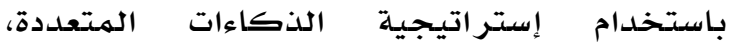
وضدابطة درست بالطريقة الاعتيادية، تم اختيارهم بالطريقة العشوائية البسيطة، أظهرت نتائج الدراسة وجود فروق ذات دلالة إحصائية

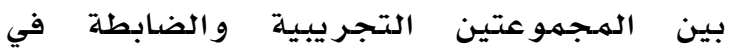
الاختبار البعدي لمستويات بلوم (التذكر و الفهم

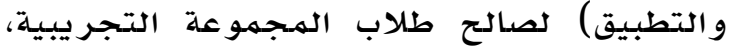
وجود فروق ذات دلالة إحصائية بين المهجمو عتين

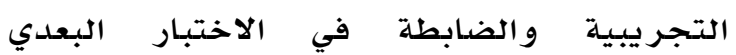

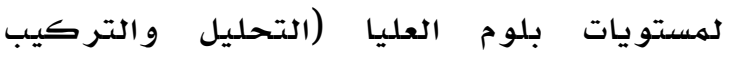

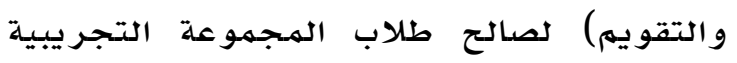

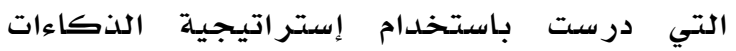

و ذلـــك فيمسا يتعلــق بمــادة الكيميـاء، و أوصــت

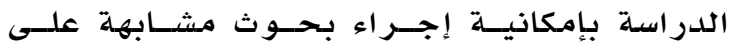
مر احل صفية و مواد أخـرى، كمهـا يـجـب إجــر اء

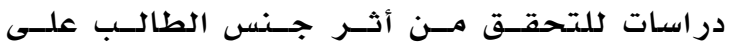
تطبيق نظرية الذكاءات المتعددة، كهـا أوصـت

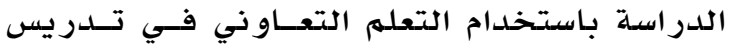

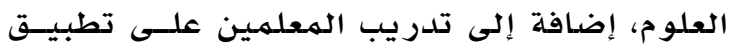

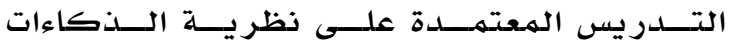
الهتعددة.

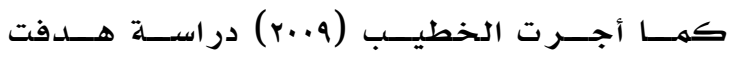

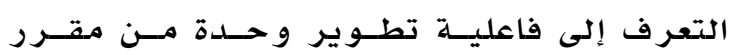

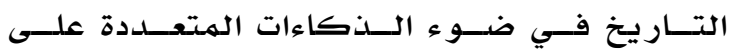

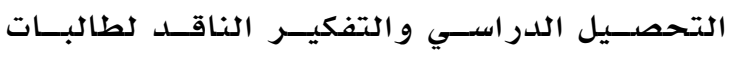

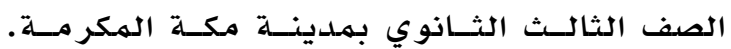

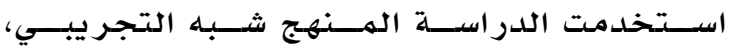

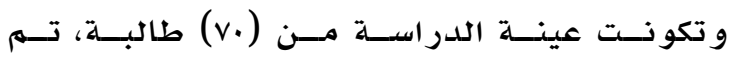
تقسـيمهن إلـى مجهمـوعتين: التجر يبيسـة درســت

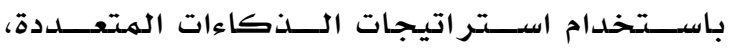

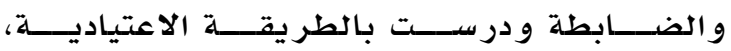
و لتحقيق اهداف الدرراســة تـهم اسـتخدام اختبــار

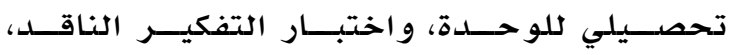

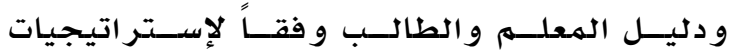
الـذذكاءات الهتعــددة، أظهـر ت نتــائج الدر اســة:

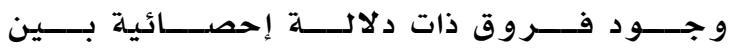

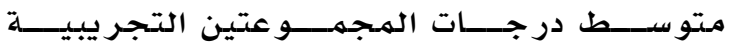

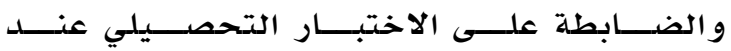

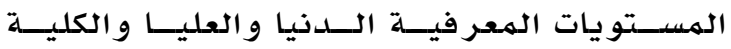

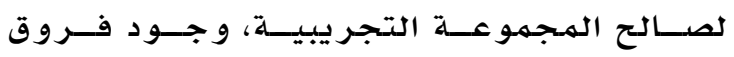

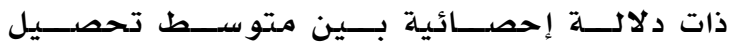

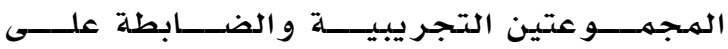

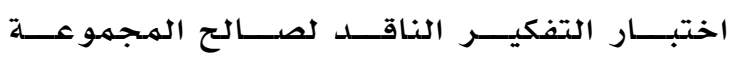
التجرر يبيـة.

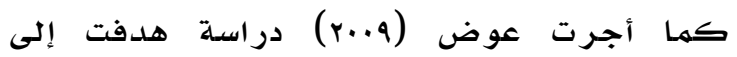
الكشف عن أثر استخدام إستراتيجية تلدريس

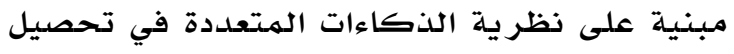
المفاهيم الفيزيائية والاتجاهات العلمية والقية القدرة

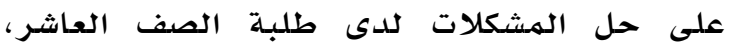

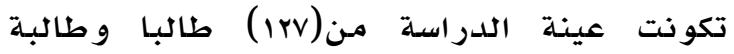
موزعين في أربع مجمهوعات، تجريبية ذلكور، 
كما قام ساهين وزملاؤه (Şahin, et al., 2010) بلدراسـة هدفت تحديد أثر استخدام إستراتيجية تلدريس قائمـة على الذكاءات الهـتعددة واتجاهات

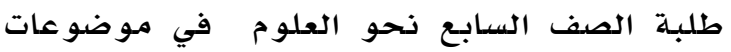

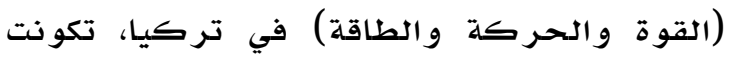
عينة الدراسة من (.ج) مشاركاً، تم توزيعهم إلى الى

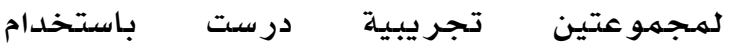

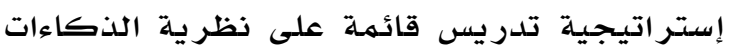

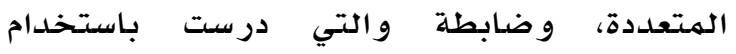
الطريقة التقليدية، ولتحقيق أهداف الدراسـة تم

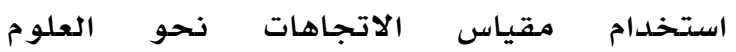
و المقابلات، أظهرت الدراسـة وجود فروق ذات

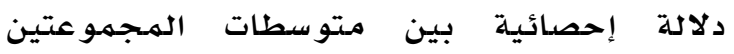

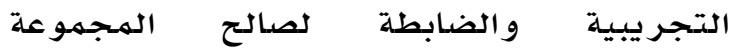
التجريبية التي درست باستخدام إستراتيجية تدريس قائمسة على نظرية الذكاءات المتعددة،

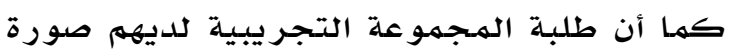

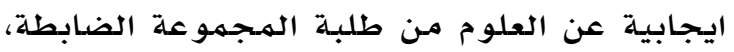

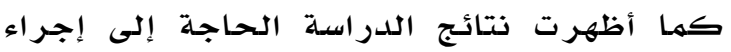

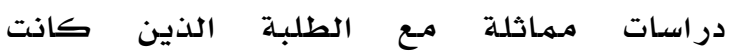
متوسطاتهم و اتجاهاتهم منـخفضـة نحو العلوم. أجمعست معظـهم الدراســات الســابقة علـى تفـوق

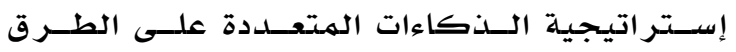

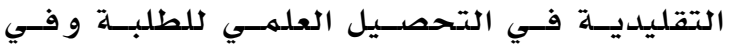

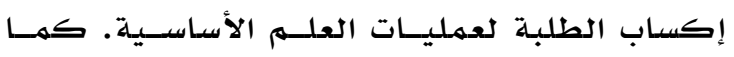

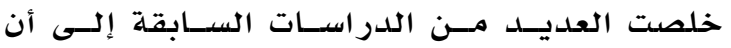

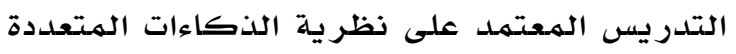
أدى إلى أن الطلبـة أظهروا سلوكات ملائمهة أثناء

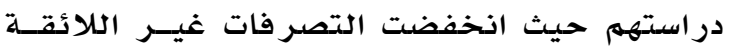

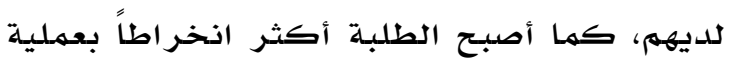

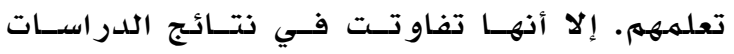

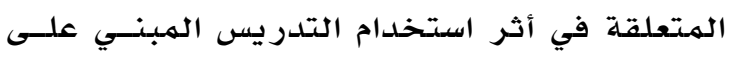
نظرية الذكاءات المتعددة في التحصـيل العلهـي التهي باختلاف الجنس.

و بالنظر إلى الدراسـات السابقة نجســ أن معظمهــا

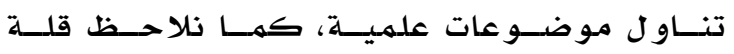

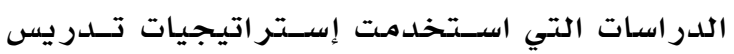
مبنية على نظرية الذكاءات المتعدددة في مبـحـث

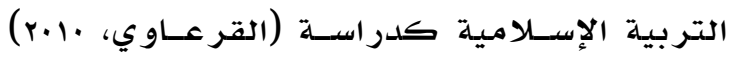

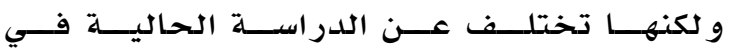

كuramı, et.al, ) كها قام كر امي وزملاؤه 2010) بدراسـة هدفت استقصداء أثر استخدام

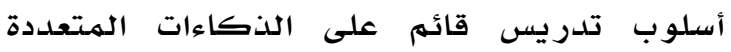

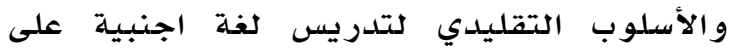

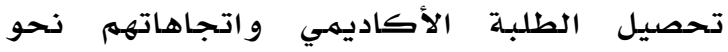
دروس اللغة الانجليزية على طلبة الهيك الهدارس

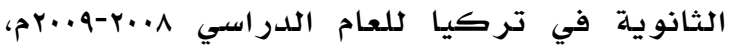

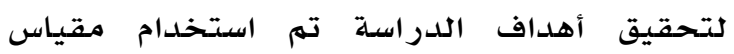
اتجاهات الطلبة نحو الدروس ومقياس تحصيل

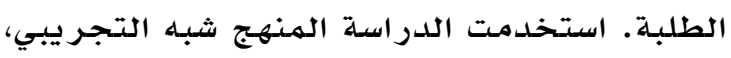

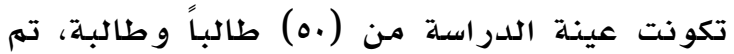

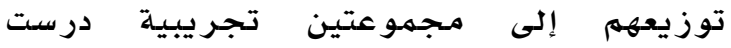

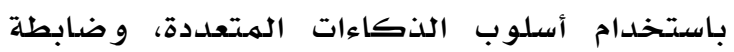

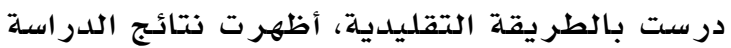

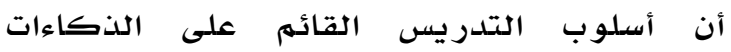
المتعددة أكثر فاعلية وحدوث تطورات ايجابية في اتجاهات الطلبة نحو دروس اللغة الانجليزية،

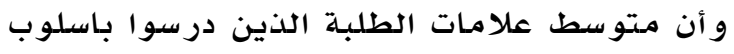

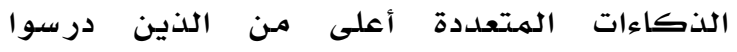
بالطريقة التقليدية و أكثر دافعية للتعله. كها قام الوحيدي و الهاشهي (.1.r) بلدراسـة

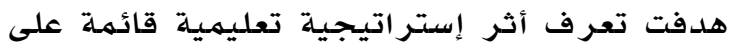

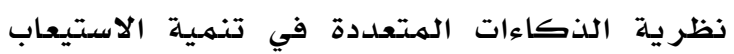

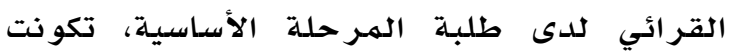

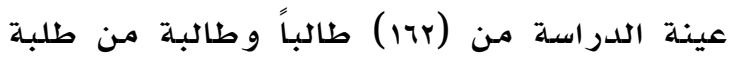

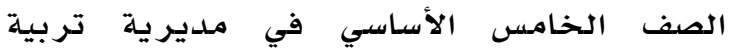

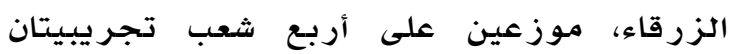

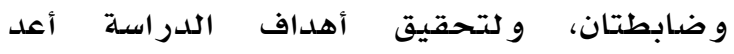

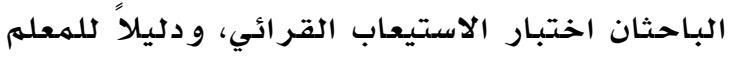

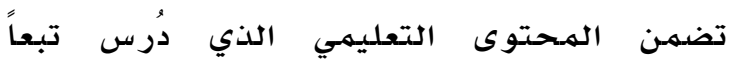

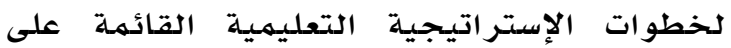

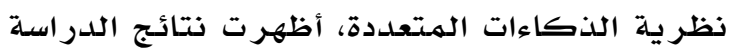
و جود فروق ذات دلالة إحصائية عند مستوى (م) فئد

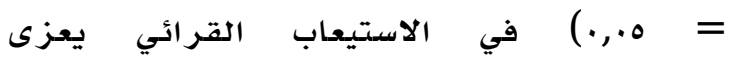

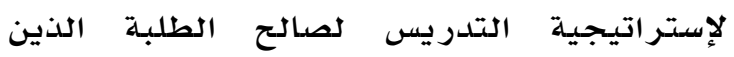

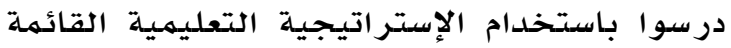

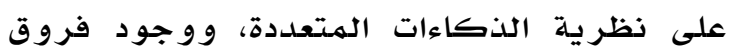
ذات دلادة إحصائية عند مستوى (م) = ه.,.•) في الاستيعاب القرائي يعزى إلى أثر التفاعل بين الإستر اتيجية و الجنس لصالح الطالبات. 
كشخصية متكاملة و التركيز على مواطن قوتـه

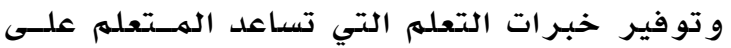

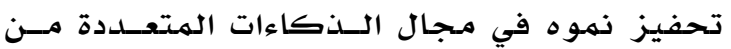
خلال تقديه المـادة العلمية التي تناسبـه. وومن هنا فقد جاءت هذه الدراسـة للبحث في أثر اســتخدام إستر اتيجية تدريس مبنية على نظرية الذكاءات

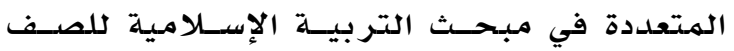

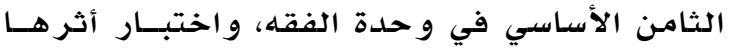
في تحصيل الطلبة للمفاهيم الفقهيـة، و تحديـدا

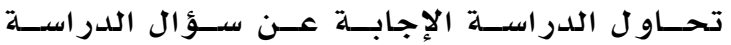
الرئيسي الآتي:- مـا أثـر اسـتخدام إســتر اتيجية تدريس مبنية على نظرية الذكاءات المتعدددة في

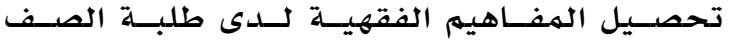

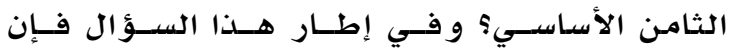
الدراسة هدفت إلى الإجابة عن السؤالين الآتيين: 1. هل يختلف تحصيل المفاهيم الفقهية لدى طلبة الصف الثامن باختلاف الإستر اتيجية

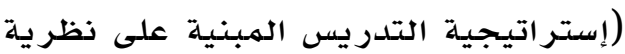

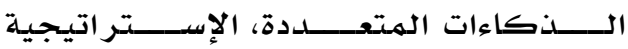

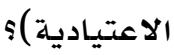

r. ـــل هنــاك أثــر فـي تحصـيل الهفـاهيم

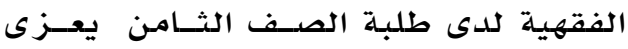

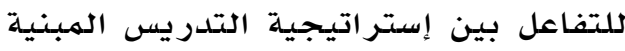
على نظرية الذكاءات المتعددة و الجنس؟

\section{فر ضيات الدراسة}

في ضوء الأسئلة السـابقة صـيغت فرضــيات الدر اسة على النحو الآتي:

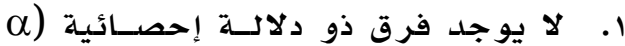

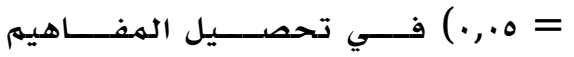
الفقهية لدى طلبة الصف الثامن يعزى

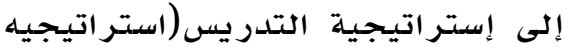

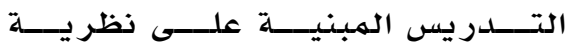

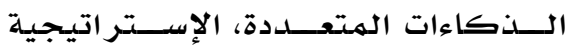

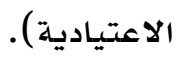
r

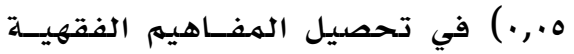
لـــى طلبـــة الصــف الثــامن يعــزى

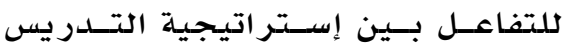

موضو عاتها و العينــة و البيئــة التــي طبقـت فيهـا والأدوات التي استخدمت في الدرواسـة.

و بنـاء علـى مـا سـبق يـرى الباحثانـأن الدراســة

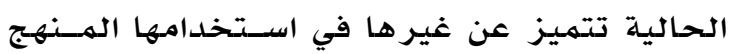
شبه التجريبي لتقصي أثر استخدام إســتراتيجية

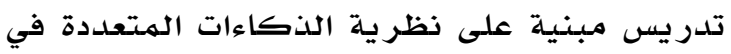

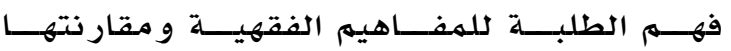
بالطريقة التقليدية، كذلك تتميز هذه الدراسـة فـي تطويرهـا للهــادة التعليميـة المبنيـة و فـق نظريــة الــذكاءات الهتعــددة وتطــوير اختبــار

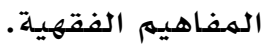

\section{مشكلة الدراسة و أسئلتها}

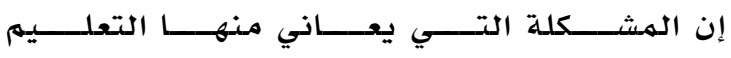

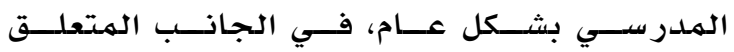

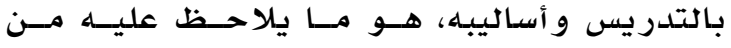

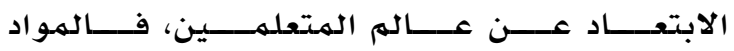
التعليهية - التعلميــة تُقـدم فـي أغلـبـ الأحيـان

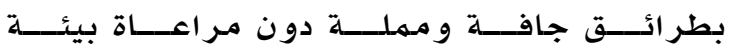

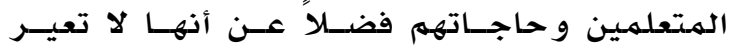

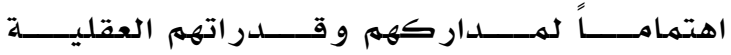

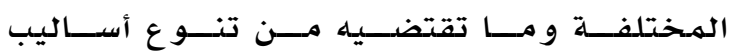

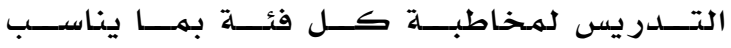

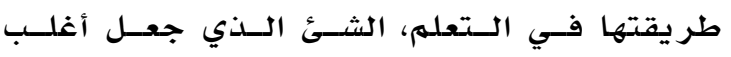

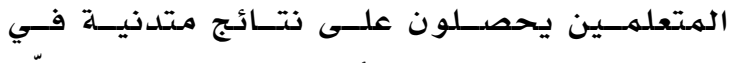

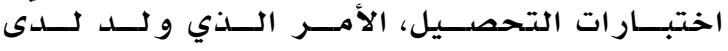

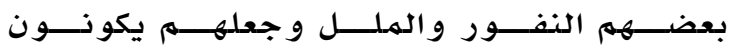

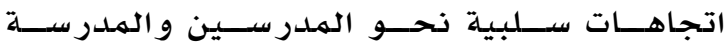

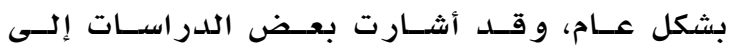

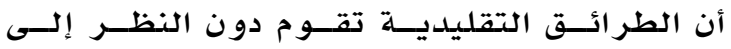

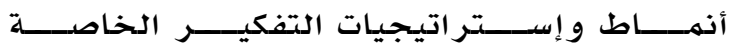
بالطلبــة، و أن التر كيـز يــتهم فــي العــادة علــى

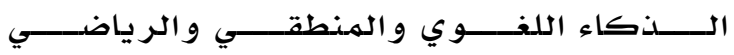
و إهمال باقي الذكاءات (Gardner, 1983) .

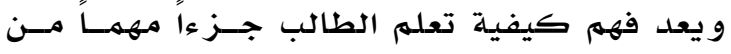

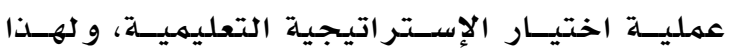

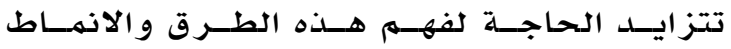

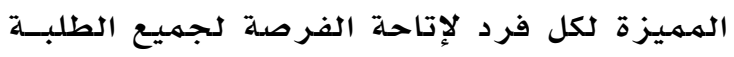

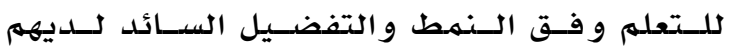

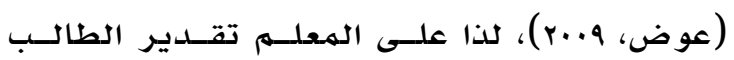


الــذكاءات المتعــددة و أســاليب تطبيقهـا،

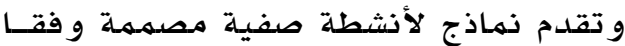
لهذه النظرية يمكن مر اعاتها أو اعتبارهـ

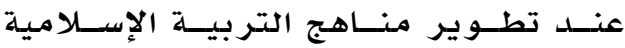
وكتبها الملدر سية، كمهـ يمكـن أن يفيسد

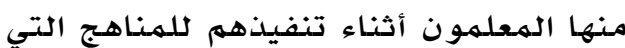
يلدر سدو نها.

محددات الدراسة - ت محة

تقتصر هذه الدر اسـة على:

- الحلدود البشرية: تطبيق الدراسة على على عينة قصدية من طلبة الصف الثامن

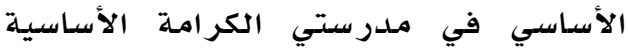
للبنات و مددرسة حي معصوم الأساسية للذكور في مديرية تربية الزرقاء الأولى

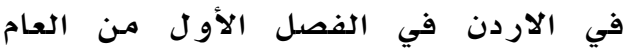

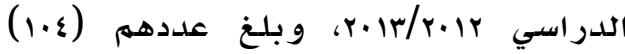
طالبا وطالبة منتظمين في أربع شعب، تهبع حيث تم تدريس المادة لشعبتين وفتق وفئ إستر اتيجية التدريس المبنية على نظرية

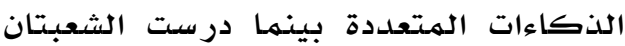
الأخريان الموضوع نفسه بالإستراتيجية الاعتيادية.

- الحدود العلمية : كما اقتصرت الدراسلة

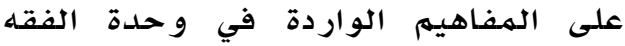

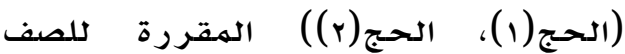

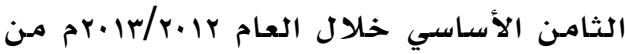

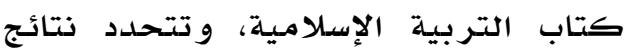
الدراسة جزئيا بالأدوات التي استخدمتها الباحثة و مدىى صدقها وثباتها، و وبالتالي

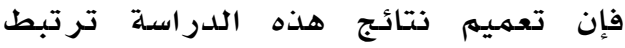
بخصائص هذه الأدوات.

مصطلحات الدر اسة

إستراتيجية التدريس المبنية على نظرية الذكاءات المتعددة

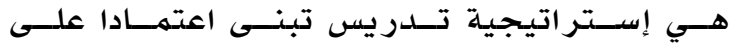

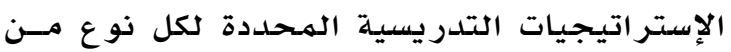

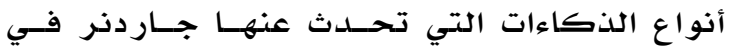
نظريته، ويتم في ظل هذه الإسـتراتيجية تقـديم
المبنيــــة علـــى نظريـــة الـــذكاءات

المتعددة و الجنس.

$$
\text { أهمية الدراسة }
$$

تنبـع أهمية الدراسة في مجالين مختلفين هما:

1- الأهميــــة النظريـــة: و تثــــــل الخلفيـــة

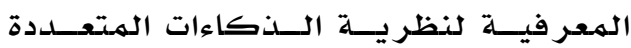

والتعريف بها والأسس التــي بنيـت عليهـا

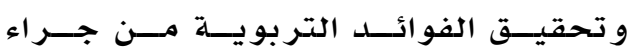

استخدام نظرية الـذكاءات الهتعـددة فــي

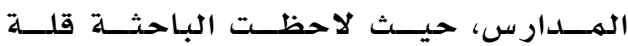

الدرر اسـات المتعلقة بموضوض

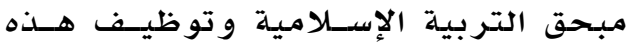
النظرية في مجال تعليهم المفاهيه الفقهية

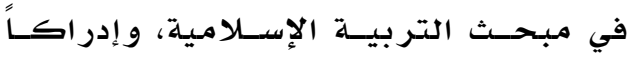
لأهميـة هذه النظريـة التعليمية جاءت هــذه

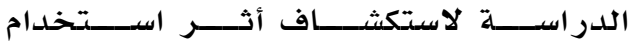

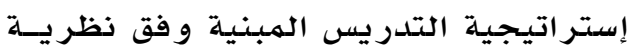
الــذكاءات المتعــددة فـي تحصـيل طلبـــة الصف الثامن الأسـاسي للهفــاهيم الفقهيـة مقارنة بالطريقة التقليدية، و مـن الممكسن المئن أن تسـهم هــذه الدر اســة بجانـب در اســات

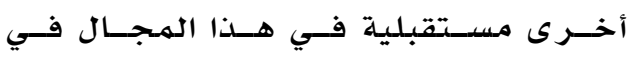
تطوير طرائق تدريس التربية الاسـلامية،

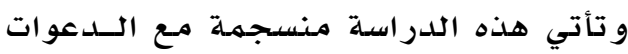

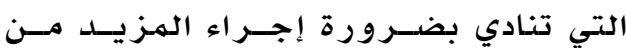

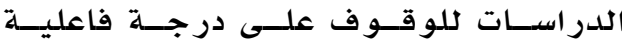
إستر اتيجيات التدريس الهعتمهدة على هــــه النظرية في تحسين التحصيل الأكساديهي و فهم المفاهيم العلمية كمها في ( Davis, )

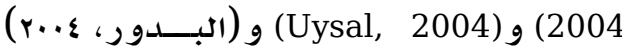

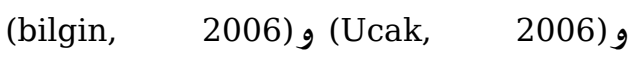
و (القر عاوي، ·. (r.1). r- الأهمية التطبيقية: فقد تم وصف عناصـر

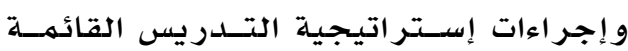

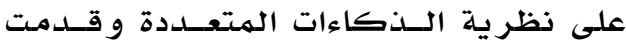

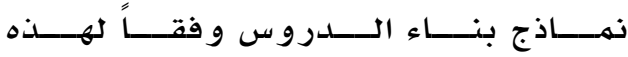
الإستر اتيجية مسما يوفر الفرصسة للمعلمسي

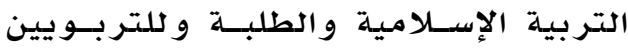
عامـة للتعر ف علـى إجــر اءات إسـتر اتيـيـية 


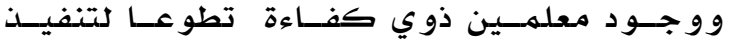

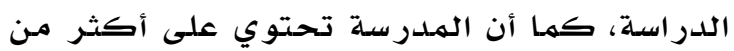

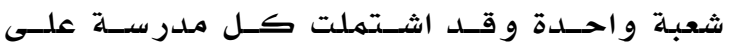
شعبتين من طلبـة الصـف الثـامن الأسـاسـي، وتـمى

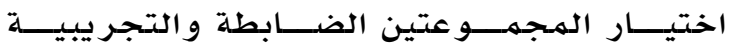
بالطريقة العشوائية البسيطة موزعتين في أربــع

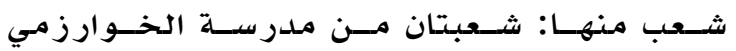
الأساسية للذكور وشعبتان من مدررسـة الكر امسـة

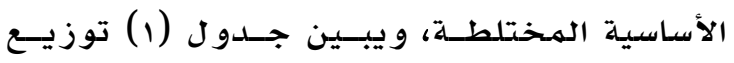
الطلبـة في المـجمو عتين التجر يبية و الضـابطة جدول

\begin{tabular}{|c|c|c|c|c|}
\hline \multicolumn{5}{|c|}{ توزيع أفراد العينة في المجموعتين التجريبية والضابطة } \\
\hline \multicolumn{2}{|c|}{ المجموعة الضابطة } & \multicolumn{2}{|c|}{ المجموعة التجريبية } & \multirow{3}{*}{ 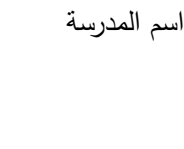 } \\
\hline عدد & عدد & عدد & عدد & \\
\hline الشعب & الطلبة & الثعب & الطلبة & \\
\hline \multirow[t]{2}{*}{1} & ry & 1 & rᄉ & مدرسة الخوارزمي \\
\hline & & & & الأساسية للأكور \\
\hline \multirow[t]{2}{*}{1} & $r \varepsilon$ & 1 & rT & إناث الكرامة \\
\hline & & & & الأساسية المختلطة \\
\hline r & 0 . & r & $0 \leqslant$ & المجموع \\
\hline
\end{tabular}

أدوات الدراسة

استخدمت في الدراسة الأدوات التالية :أو لا: أداة مسع الذكاءات المتعددة

قامست الباحثـة ببنــاء أداة مســح الــذكاءات المتعددة و فق الإجر اءات الآتية:

(McCkenzie, تم اسـتختدام أداة مـاكنزي

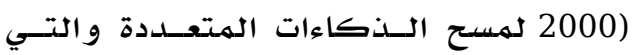

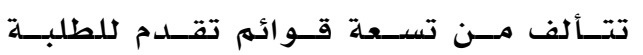
وتختبر كل قائهمة نوعاً واحداً من أنـواع

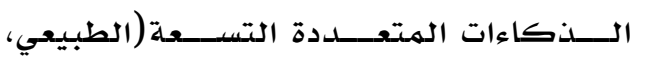

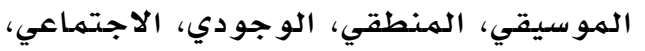

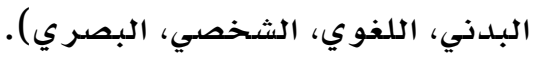
تــم حسـذف كـل مــن الــذكاء الوجـودي والذكاء الطبيعي لتصـبـح الأداة مقتصـرة

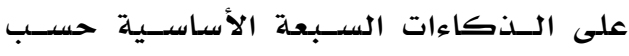
تصنيف جار دنر (Gardner, 1983). تمت ترجمة الأداة و تعديلها لتوافق البيئــة

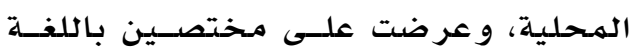

الهفـاهيهم الفقهيـة مــن خـالال أنثــطة صــية

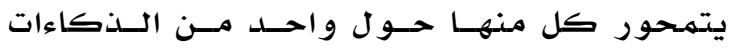
السـبعـة، بحيـث تسـتجيب للتفضـيلات التعلميـة للطلبـة و أنماط الذكاء السـائدة لديهم. إستراتيجية التدريس الاعتيادية

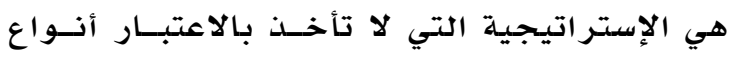

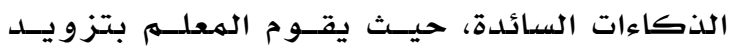

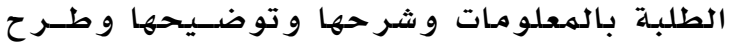

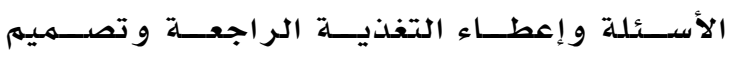

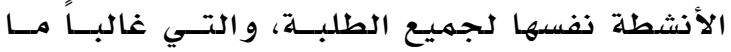

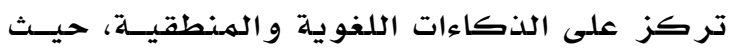

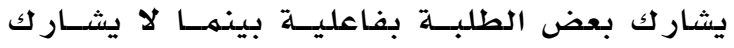

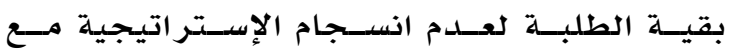
تفضيلاتهم و أنماط الذكاء السائدة لديهم. تحصيل المفاهيم الفيزيائية: قدرة الطلبـة على المقاء

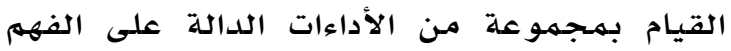
(يفسر، يتنباً، يطبق المعرفة في سياقات جديدة الادراء)،

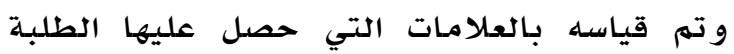
على اختبار تحصيل المفاهيم الفقهية الذي صمهم خصيصا لهذه الدراسة و الذي يقيس تحصيل الطلبة لهذه المفاهيم في مستوى التذكر و الفهم و الاستيعاب و المستو يات العقلية العليا.

\section{الطريقة والإجر اءات}

مجتمع الدراسة وعينتها

تكــون مـجتمهـع الدراســـة مــن جميــع طلبـــة

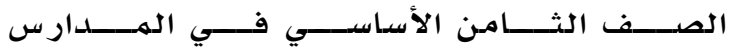

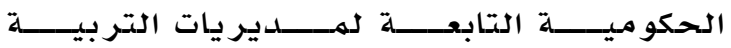

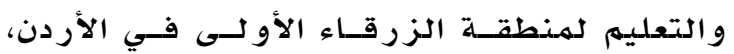

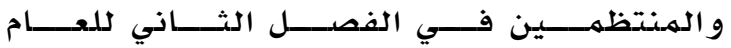

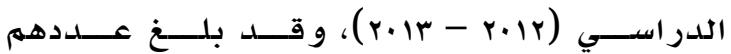

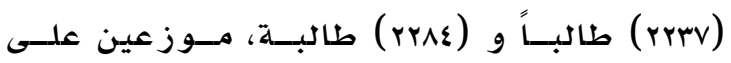

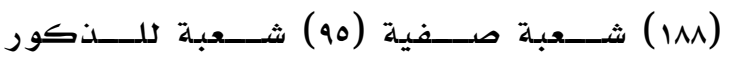
(ه) ) شعبة كلإِناث.

عينة الدراسة تكونت عينة الدراسـة من (ع.1) طالباً وطالبة من مدرستين إحداهما للذكور والأخرى للإناث، تسم

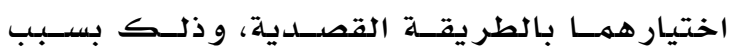




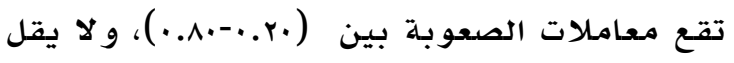

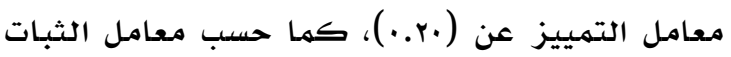

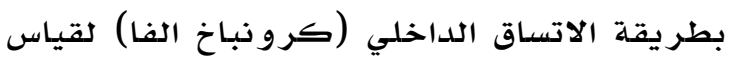

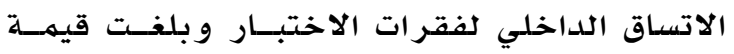

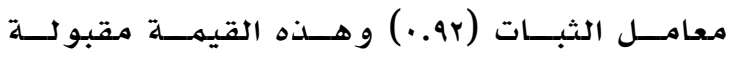

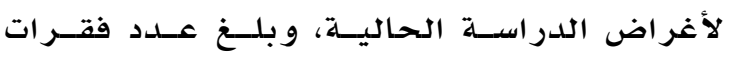

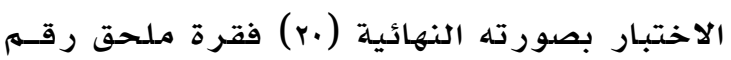

\section{ثالثا: إعداد المادة التعليمية المبنية وفق نظرية}

\section{الذكاءات المتعددة}

ا. قبل البدء بتصميهم المـادة التعليميـة قامست

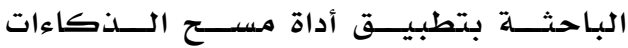
المتعددة التي ووصـفها (Mckenzie, 2000)

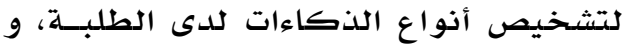

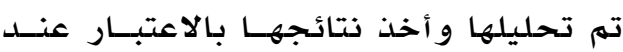
تصميم الوحدة الدر اسية ملحقى رقمى (ع). r. تمــت مـر اجعــة الأدب التربـوي و البحسورث و الدر اسـات السابقة التي تناو لـت اسـتخدام إستر اتيجيـة تــــيس مبنيــة علـى نظريسـة الذكاءات المتعددة في التدريس بشكل عام وفـي تـدريس التربيـة الإســلامية بشـكل

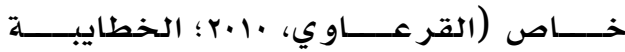

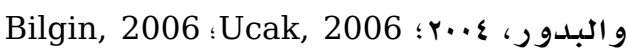
(Davis, 2004.

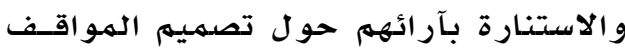
التعليمية وفق نظرية الذكاءات المتعددة. r. اعتماد تحليل محتوى الفصـول المختــارة من وحدة الفقه و المفاهيم الفقهية التسي

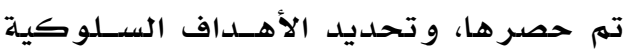
المتوقع تحقيقها لدى الطلبة. ع. إعداد المـادة التعليمية التي تتضـهـن إعـادة

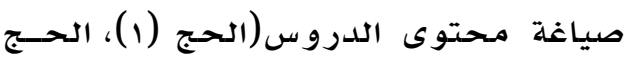

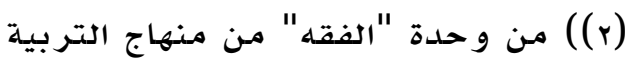

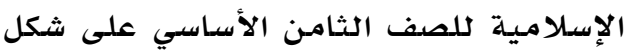
نشـاطات تناسـب إسـتر اتيجيات التــدريس

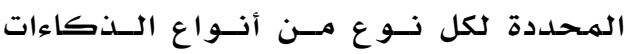

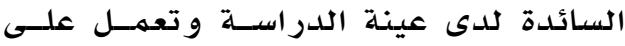

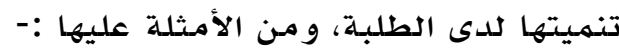

العربية واللغــة الإنجليزيسـة للتأكسـد مــن سلامة الترجمـة و أمانة التعريب. تمت مقارنـة الأداة مــع ترجهــة وتعريسب

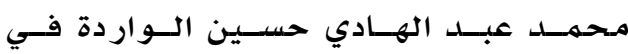

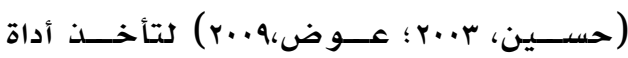
مستح الذكاءات المتعددة صورتها النهائية، ملحق رقم(1). تم تطبيـق الأداة بعـــ أن أخــدت صـورتها

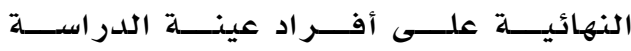

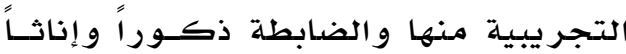

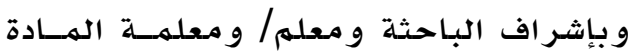

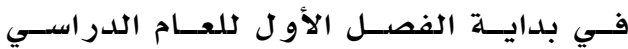

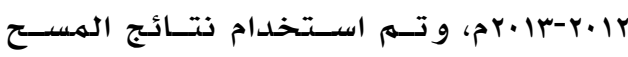

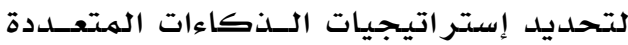
التي تم اعتمادها في بناء المادة التعليمية.

ثانيـا: اختبـار تحصسيل المفـاهيم الفيزيائيـة: استخدم الباحثان أساليب علمية معروفة في بناء

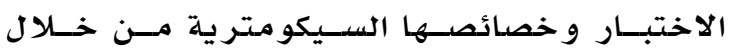

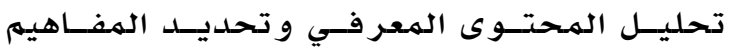

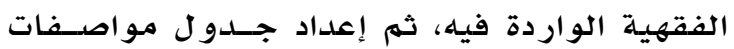

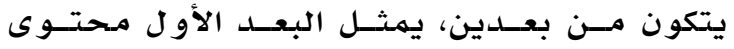

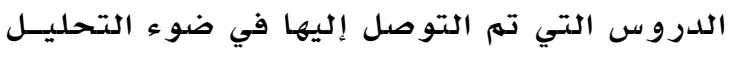

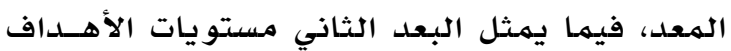

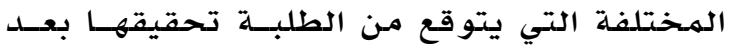

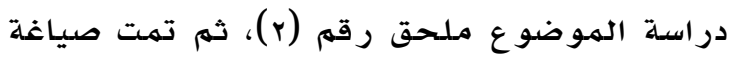

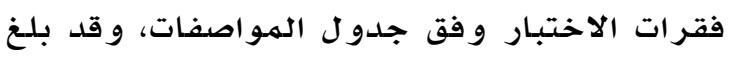

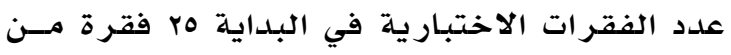
نوع الاختيار من متعدد حسب مستويات الأهـداف

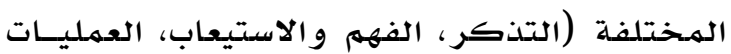

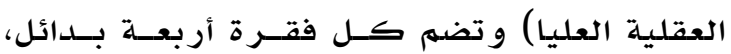

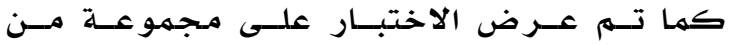

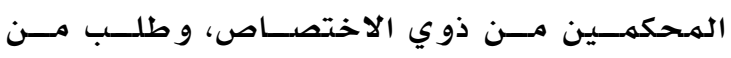

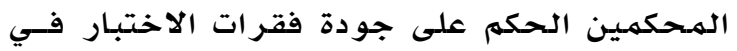

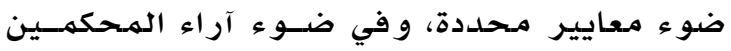

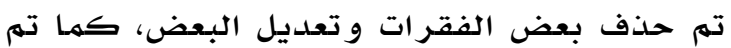
تطبيق الاختبار على عينة استطلاعية تألفت مـن

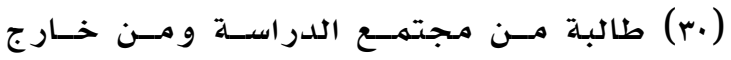

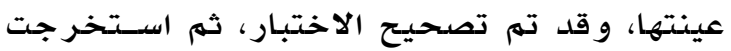

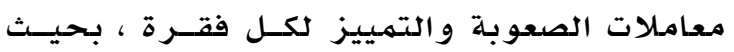


ووضوح لغتها، و أجريت التعديلات اللازمة

بناء على آر ائهم ملحق (ه) (ه).

\section{إجراءات الدراسة - (إسة}

شملت هذه الإجر اءات مجموعة من الخطوات من

أهمها:-

بعد إعداد أدوات الدراسة و المـادة التعليمية المبنية وفق نظرية الـذكاءات المتعسددة،

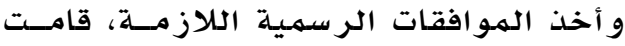

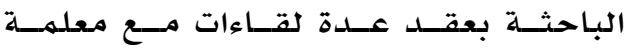
التربية الإسلامية للصف الثـامن الأساسـي

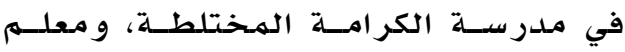

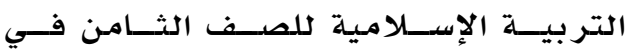

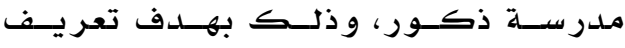
المعلمين بأهداف الدراسة، و بإسـتر اتيجية التدريس المبنية علـى نظريــة الــذكاءات المتعددة و تدر يبههم على توظيفها. جمهـ البيانات القبلية عـن عينــة الدراســة فيما يخص تحصيل المفاهيم الفقهية.

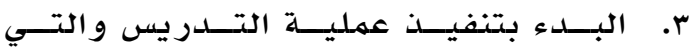
استغر قت ستة أسـابيع حيسث تـم تـدريس المجموعة التجريبيسة وفـق إسـتر اتيجية

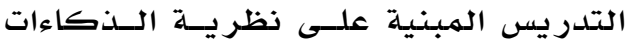

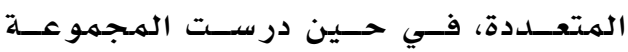

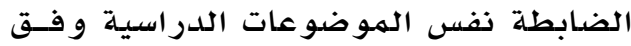

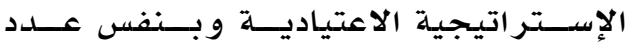
|نحصט ع. تــم التطبيـق البعسدي لأداة الدراســة بعـــ

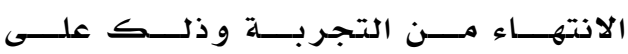
مجموعتي الدر اسة، ثم تم تصسحيح أوراق الاختبــار مسن قبـل الباحسث و معالجتهـا إحصائيا.

\section{المعالجة الإحصائية}

من أجل معالجة البيانات ومسن ثـهم الإجابسـة عـن

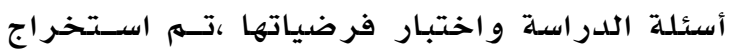

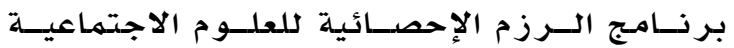

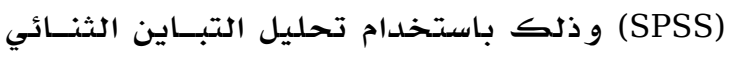

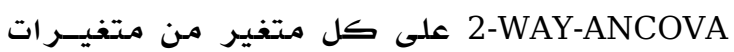

ه إســر اتيجيات السـذكاء اللغــوي:- مثـلـ

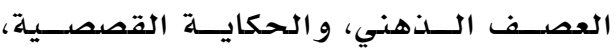
وكتابة اليوميات.

• إســتراتيجيات الــذكاء الر ياضــي:- مثـل

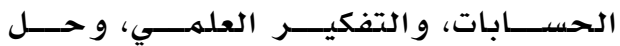

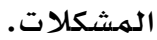

إســـر اتيجيات الــذكاء المكـــاني:- مثـلـل التخيل البصري، والأفكار المصورة.

إسـتراتيجيات الـذكاء الحركـي:- مثـل مسرح الصف، والتمثيل، وخر ائط الجسم.

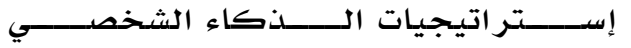

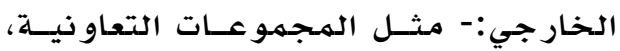
و مشار كة الأقر ان.

إستر اتيجيات الذكاء الشخصي الداخلي:مثل الارتباط الثخصي، وجلسـة تحديسيد

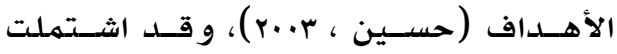

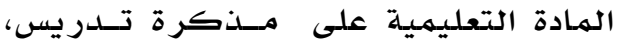
وتم تقسيم الخطــة الدر سـية إلـى ثـلاث

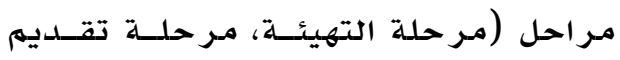

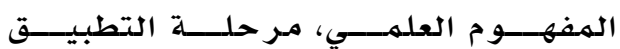

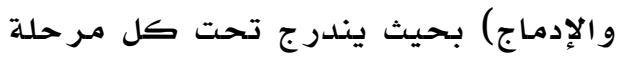

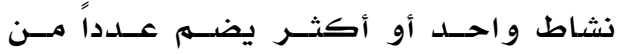
الإجــراءات التـي تخسـدم تنفيــذ النشــاط.

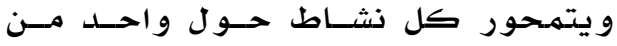

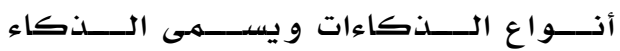

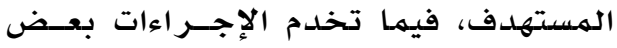

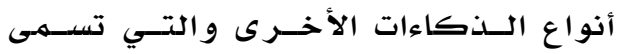
الذكاءات الداعمة. الداء.

ه. حكمت المواقف التعليمية بواسطة ستة من

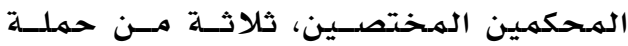

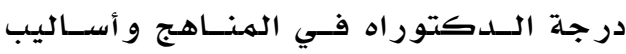

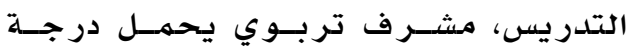
الماجستير في المناهج و أساليب التدريس، بالإضافة إلى معلم و معلمة تربية إسلامية

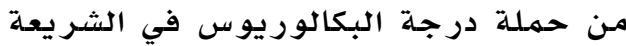
الإسلامية، حيث طلب منهم تحكيم المـادة العلمية في ضوء ملاءمتها لمستوى الطلاب و الأهـــداف التعليميسـة، ودوقــة صــــاغتها، 
يتضح من جدول (r) وجود فرق (ظاهري) بـين متوسط علامـات الطلبسـة علـى اختبـار تحصسيل

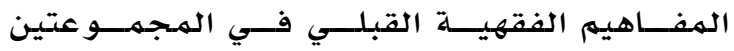

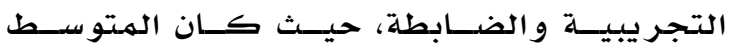

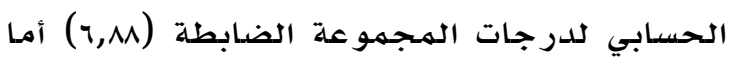

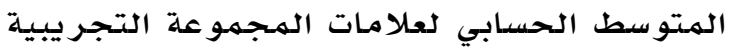

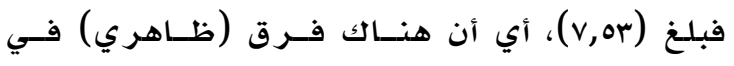

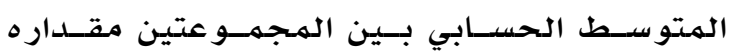

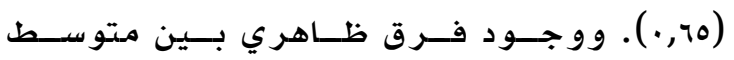
علامات الذكور والإنـاث علـى اختبـار تحصسيل

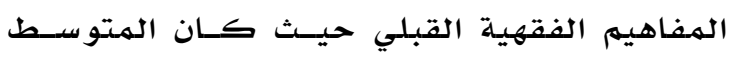

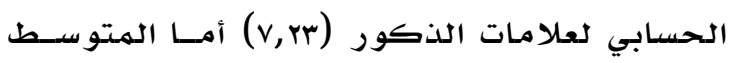

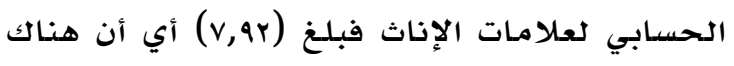

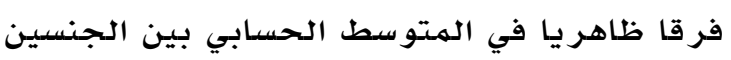

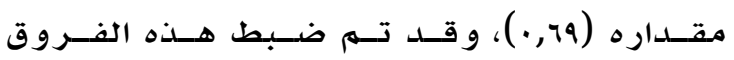

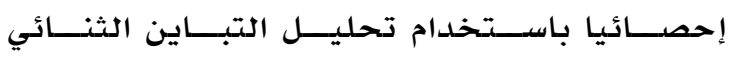
المشتر ك (2-Way ANCOVA). كذلك يظهر جــدول رقــم (r) أن هنـاك فرقـا

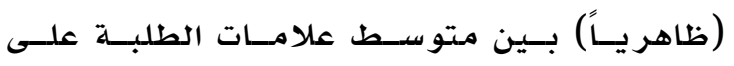

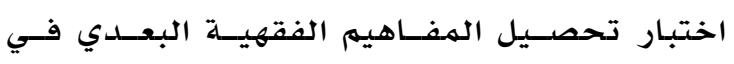

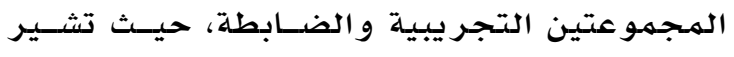

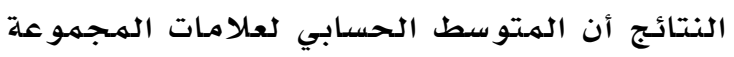

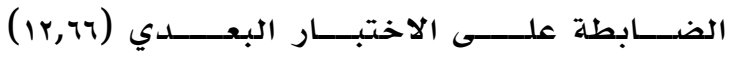

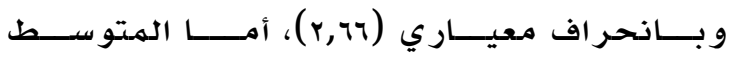

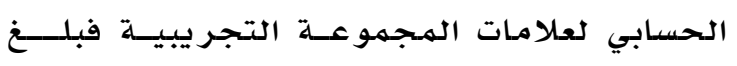
(iv, ( ) و بانحسر اف معياري (1,Vr)

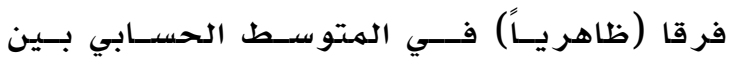

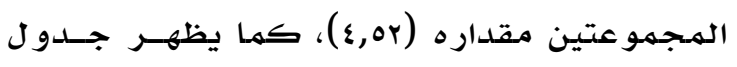

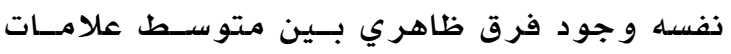

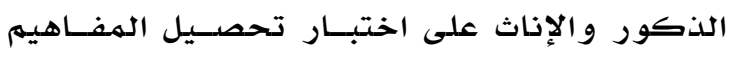

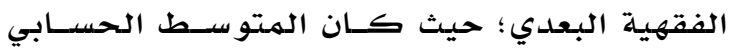

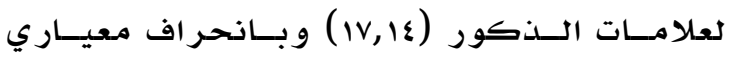
(I,VV)

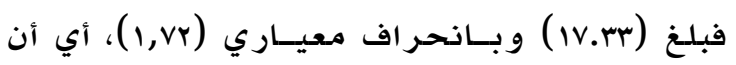

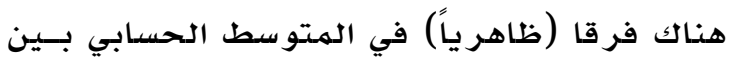
الجنسين مقداره (9., •).

و لمعر فة مستوى الدلالة الإحصائية للفروق بـين

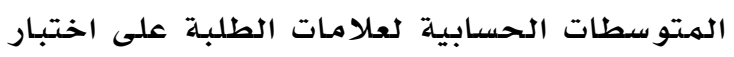

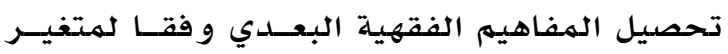

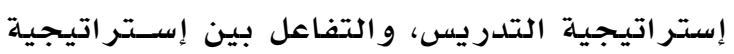

الدراسة تحصيل المفاهيم الفقهية عنسـد مسـتوى

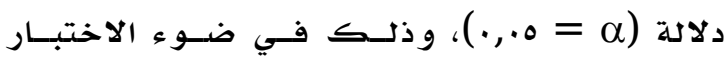
القبلي الذي تم تطبيقه قبل بدء الدر اسة.

\section{نتائج الدراسة}

حاو لت هـــه الدراســة الإجابـة عـن الأسـئلة

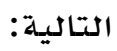

1. هل يختلف تحصيل المفاهيم الفقهية لدى

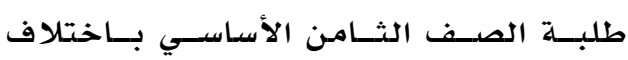

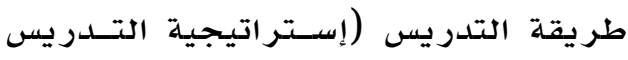

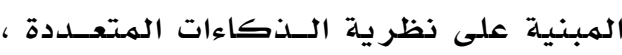

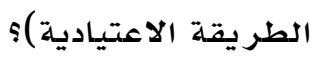

r. هـل هنـاك أثـر فـي تحصـيل المفـاهيم الفقهية لدى طلبة الصف الثامن الأساسيسي

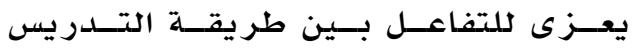

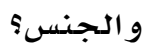

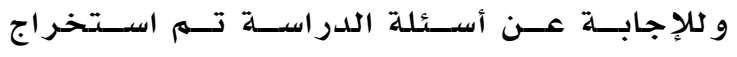

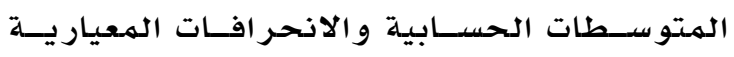

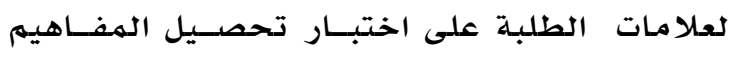

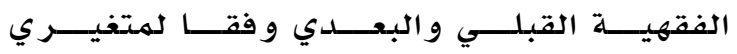

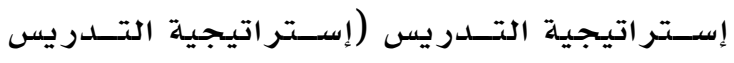

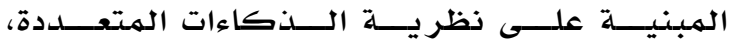

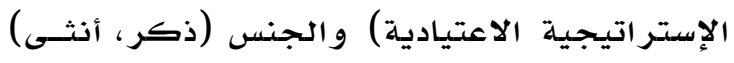
وكانت النتائج كما في جدول الاعتيادية والجنئ

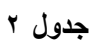

المتوسطات الحسابية والانحرافات المعيارية لعلامات طلبة المجموعتين

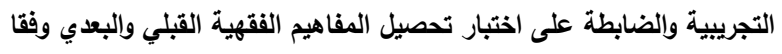

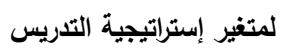

\begin{tabular}{|c|c|c|c|c|c|}
\hline \multicolumn{2}{|c|}{ الاختبار البعدي } & \multicolumn{2}{|c|}{ الاختبار القبلي } & \multirow{2}{*}{ الإصفية اءات } & \multirow{2}{*}{ الجنس } \\
\hline التجريبية & الضابطة & التجريبية & الضابطة & & \\
\hline$|v,| \varepsilon$ & 14,70 & $V, q Y$ & $V, r T$ & الكتوسط الحسابي & \\
\hline l,VV & $r, \varepsilon \varepsilon$ & 1,7 . & $r, I V$ & الانحراف المعياري & الذكور \\
\hline ru & r & r^ & T & العدد & \\
\hline IV,rT & 11,01 & $v, 11$ & $7,0$. & المتوسط الحسابي & \\
\hline l,Vr & $r, 01$ & $\curlyvee, \varepsilon$. & $1, v \varepsilon$ & الانحراف المعياري & الإناث \\
\hline$r \varepsilon$ & r & $r \varepsilon$ & r4 & العدد & \\
\hline$|V| A$, & $1 T, T 4$ & v,or & $\uparrow, \wedge \curlywedge$ & المتوسط الحسابي & \\
\hline l,Vr & $r, T 4$ & $r, .0$ & 1,99 & الانحراف المعياري & الدجموع \\
\hline $0 \varepsilon$ & 0. & $0 \leqslant$ & 0. & العدد & \\
\hline
\end{tabular}

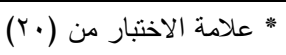


على أدائهما في الاختبار البعدي، وكانت النتائج

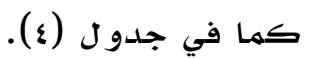
جدول ؛

المتوسطين الحسابيين المعدلين لعلامات الطلبة

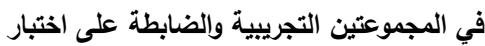

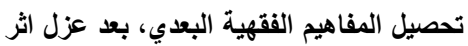

\begin{tabular}{|c|c|c|}
\hline \multicolumn{3}{|c|}{ الأداء على الاختبار القبلي } \\
\hline المعياري & المعتول & المجموعة \\
\hline$\cdot, \leq 7$ & $r \varepsilon, Y \cdot q$ & التجريبية \\
\hline$\cdot, \leqslant \wedge$ & $19, \varepsilon \wedge \varepsilon$ & الضابطة \\
\hline
\end{tabular}

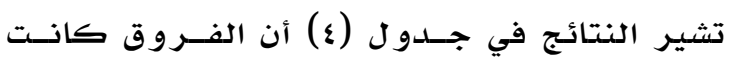

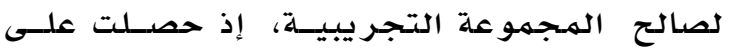

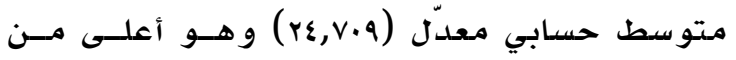

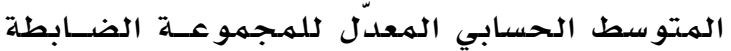

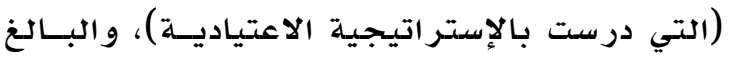
( التدريس المبنية على نظرية الذكاءات المتعددة يؤدي إلسى تحسـين تحصـيل الطلبسـة للمفـاهيم

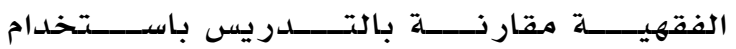
الإستر اتيجية الاعتيادية.

التدريس و الجنس، وبهدف عزل الفروق فـي أداء الطلبة علـى الاختبـار القبلـي، استـتخدم اختبـار تحليـل التبــاين الثنــائي المشـــتر ك

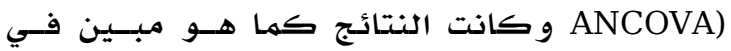

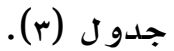
تظهر النتائج في جدول رقم (r) وجود فرق دال

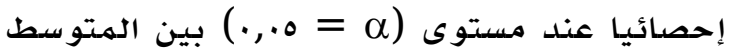
الحسابي لعلامات الطلبة على اختبار تحصيل

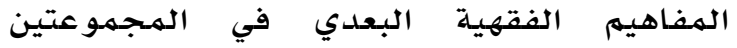

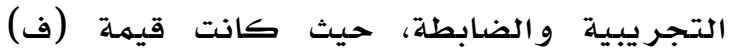

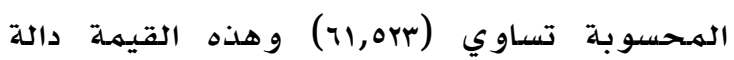

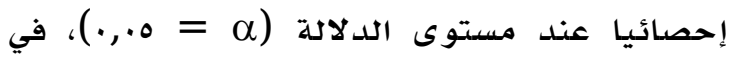
حين تظهر النتائج عدم وجود فرق دال إحصائيا

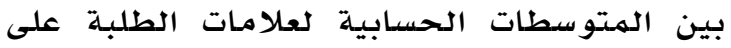

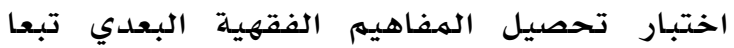
للتفاعل بين إستر اتيجية التدريس و الجنس. و لتحديد قيمة الفروق في متوسطات علامات الطلبة في المجموعتين التجريبية و والضابطة

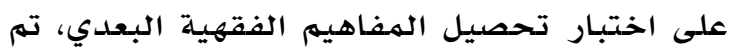

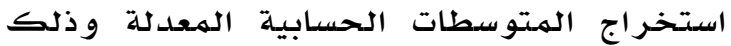

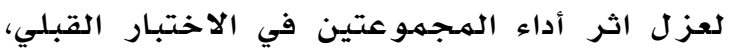

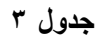

نتائج تحليل التباين المشترك (ANCOVA) لعلامات طلبة مجموعتي الدراسة على اختبار تحصيل الدفاهيم الفقهية البعدي وفقا لمتغيري إستراتيجية التدريس والجنس والتفاعل بينهما

\begin{tabular}{|c|c|c|c|c|c|}
\hline مستوى الدلالة & قيمة ف المحسوبة & متوسط المربعات & درجات الحرية & مجموع المربعات & مصدر التباين \\
\hline$\cdot, \cdots$ & $\leq \varepsilon \cdot 1,0.1$ & $0 . T T V, r T V$ & 1 & $0.7 T V, r T V$ & المشترك (القبلي) \\
\hline$* \cdot, \ldots$ & אוד & $V \cdot V, 74$. & 1 & $V \cdot V, 74$. & إستراتيجية التدريس \\
\hline$\cdot, \cdots 9$ & $v, \cdots v$ & $\Lambda \cdot, 091$ & 1 & $\Lambda \cdot, 09 \wedge$ & الجنس الجس \\
\hline \multirow[t]{3}{*}{$\cdot, I T K$} & $r, \varepsilon r \wedge$ & $r v, 94$ & 1 & $r V, q T$ & إستراتيجية التدريس * الجنس \\
\hline & & $11,0 . r$ & $1 \ldots$ & $110 \cdot, r$ rq & الخطأ \\
\hline & & & $1 . \varepsilon$ & orro.,... & الكلى \\
\hline
\end{tabular}




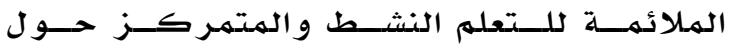
الطالب، و الذي يحقق مبادئ النظرية البنائية فـي

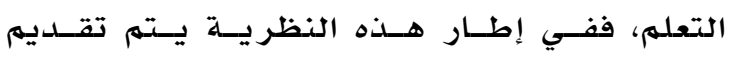

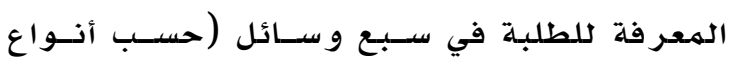

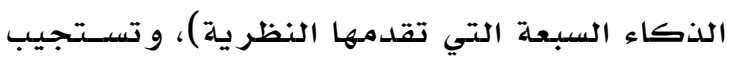
بذلك للتنوع و الفروق لدى الطلبة جاعلة التعلهم

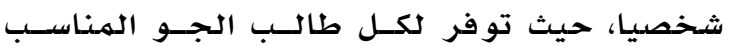

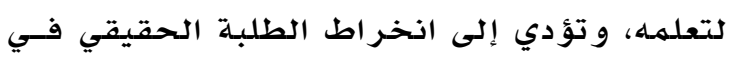

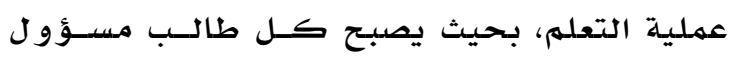

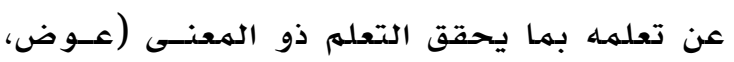
(r...q وتقدم نظرية الذكاءات المتعددة صورة مغايرة للغر فة الصفية و ما يتم داخلها من أنشطة، حيسث

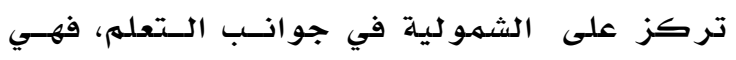

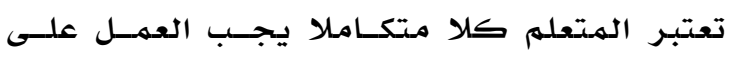

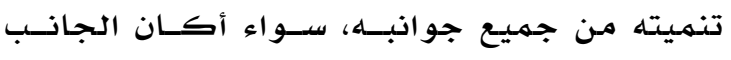

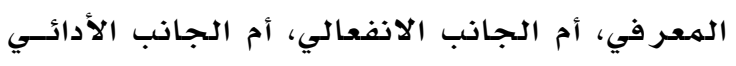

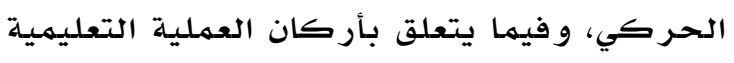

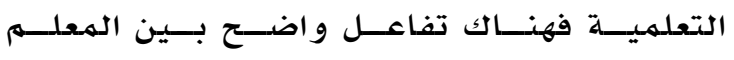
والهتعلهم، بل إن هناك شـر اكة حقيقيـة بينهمــا،

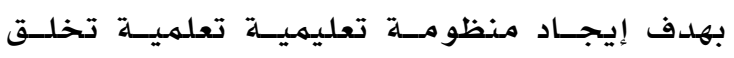

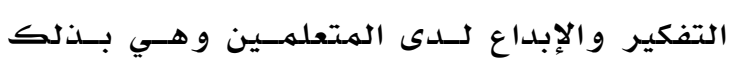

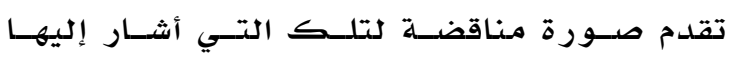

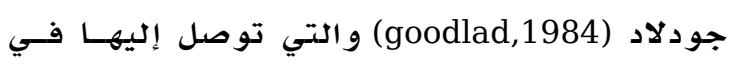

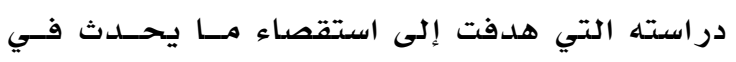

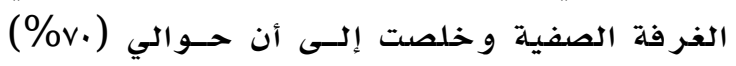

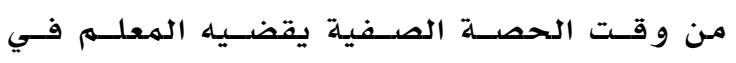

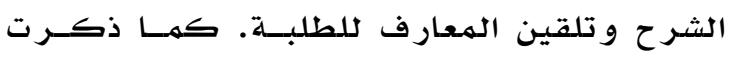

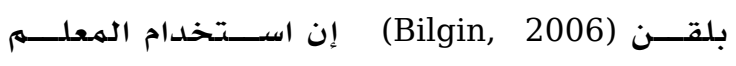

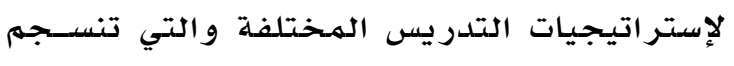

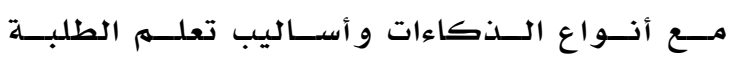

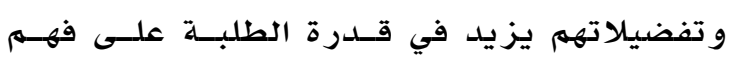

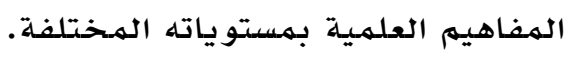

\section{مناقشة النتائج المتعلقة بالسؤال الثاني:}

نص السؤال الثاني علـى: هـلـ هنــاك أثـر فـي

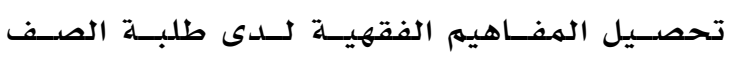

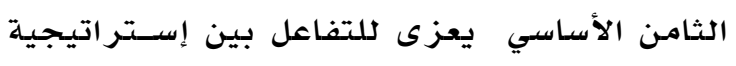

\section{مناقشة النتائج}

مناقشة نتائج السؤال الأول: هل يختلف تحصيل

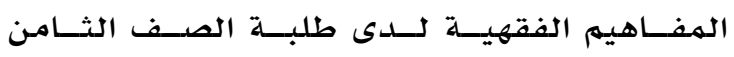

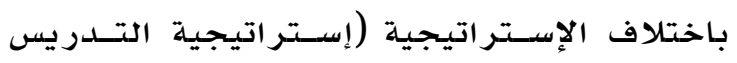

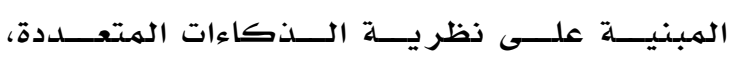

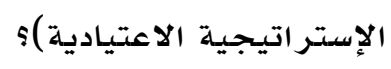

أظهرت نتائج تحليل السؤال الأول أن هناك فرقا

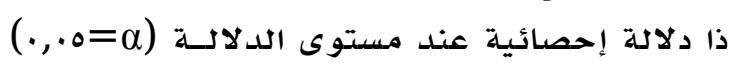

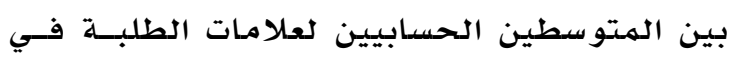

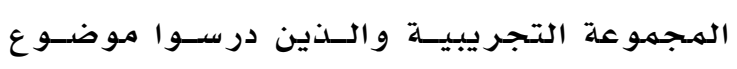

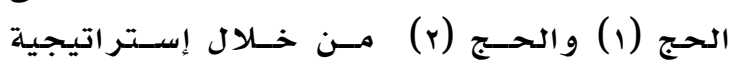

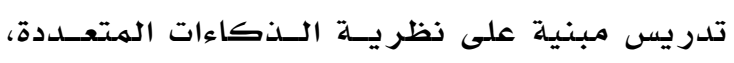

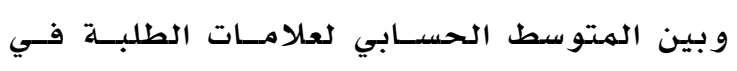

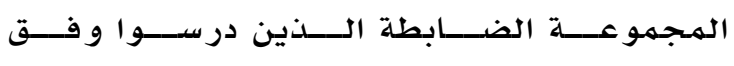

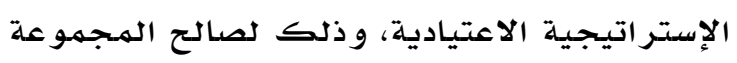

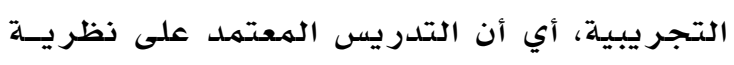

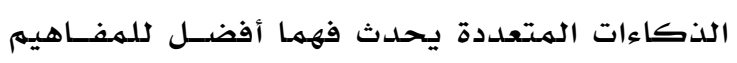

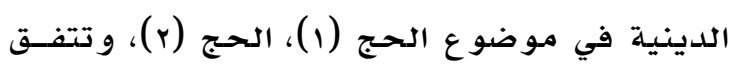

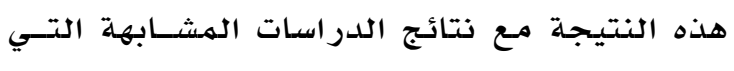

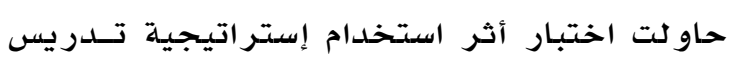
مبنية على نظرية الذكاءات المتعددة في تحصيل

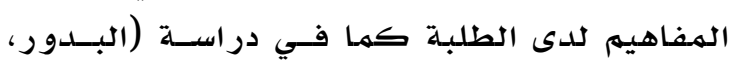

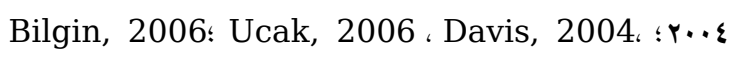

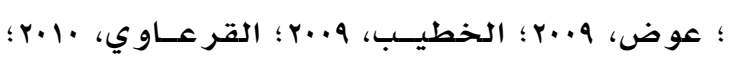

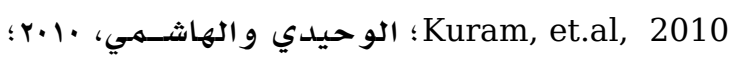

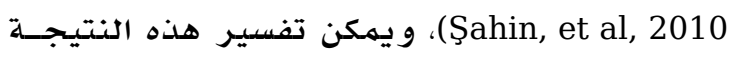

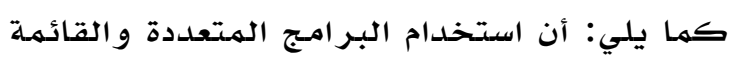

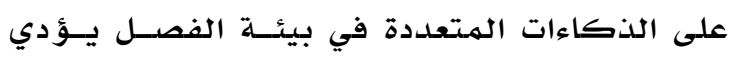

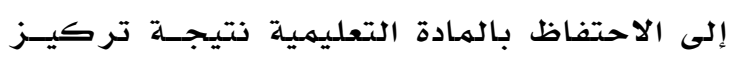

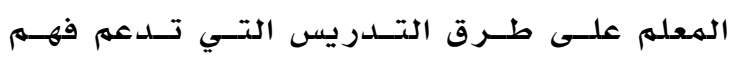

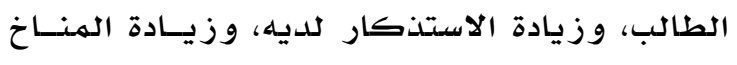

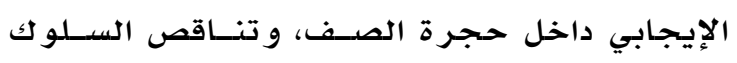

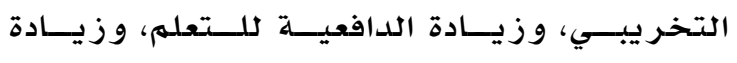

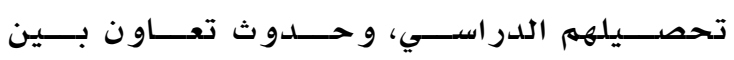

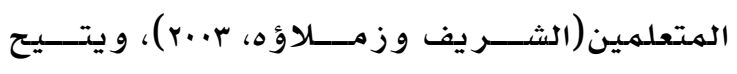
الفر ص للمتعلهم ليجسر الهوة بين التعلهم الجديد

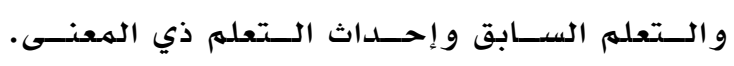

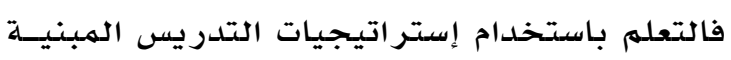

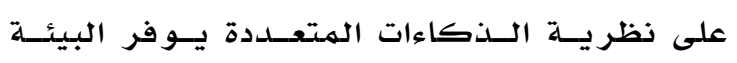




\section{المراجع}

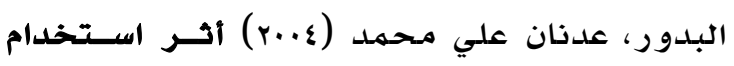
إستر اتيجيات الذكاءات المتعددة في تدريس العلوم في التحصيل واكتساب عمليات العلم

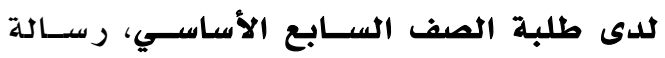

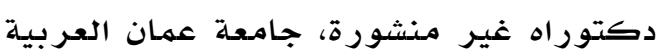
للدر اسـات العليا، عمان، الأردن.

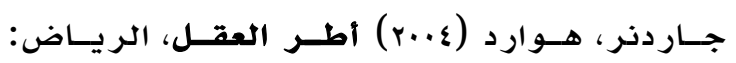
مكتبـة التربية العربية لدو لـول الخليج.

حسين، محمد عبد الهادي (r.r.r) قيـاس وتقيـيم قدرات الذكاءات المتعددة، عمان: دار الفكر للطباعة و النشر • لـثراب

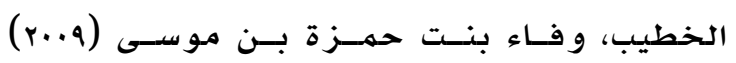

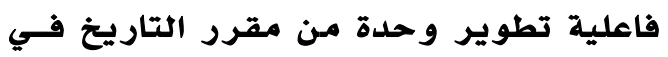
ضوء الـذكاءات المتعـددة علـى التحصــيل والتفكير الناقد للى طالبات الصف الثاتـث الثــانوي بمدينــة مكــة المكر مـــة، رســالة

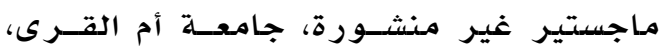
مكة المكر مـة.

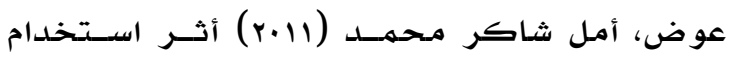
إستر اتيجية مبنيـة علـى نظريــة الـذكاءات المتعددة في تحصديل المفـاهيهم الفيزيائيسة

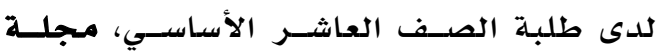

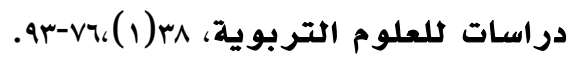
نوفل، محمد بكر (r..v ). الذكاء المتعـدد فـي

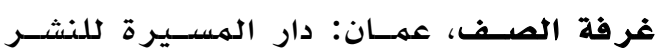

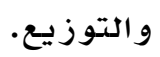

الشـر يف صــلاح الــدين حســين و محمهــل، إمـام

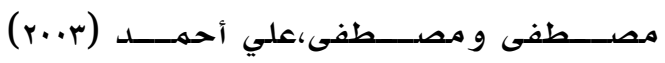
الاتجاهـات الحديثــة فــي قيـاس الــذكاء والذاكرة البشرية، الرياض: دار الزهر اء.

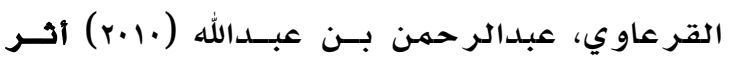

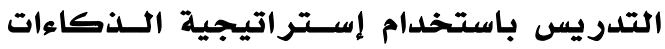

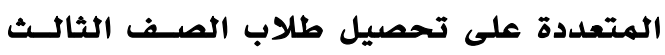
المتوسط في مقرر الفقه، رسالة ماجسـتير

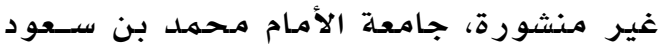

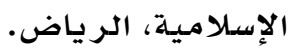

التدريس الهبنية على نظرية الذكاءات الهتعددة و الجنس؟ تبين من خلال تحليل نتائج السؤال الثاني أنــه لا

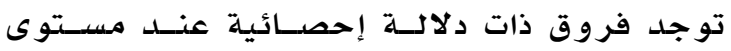

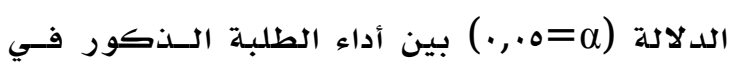

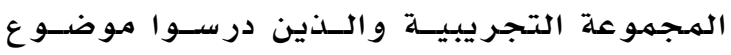

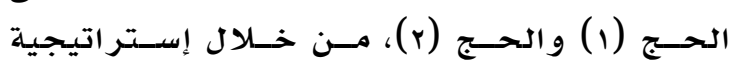
تلدريس مبنية على نظريــة الـذكاءات المتعـددة،

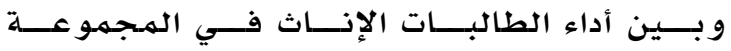

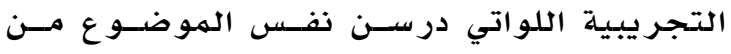

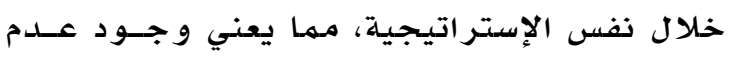

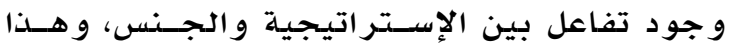

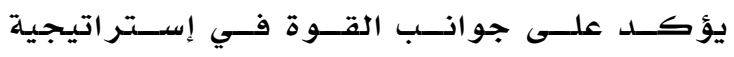

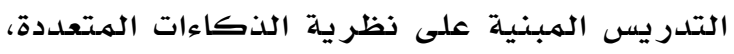

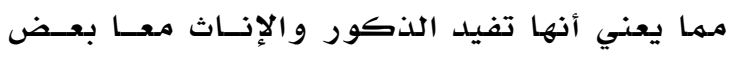

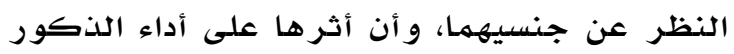

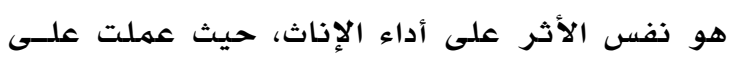

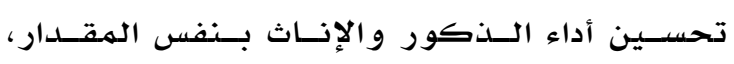
و هذه النتيجة تتفق مـع النتيجة التي توصل إليها

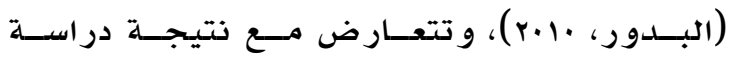

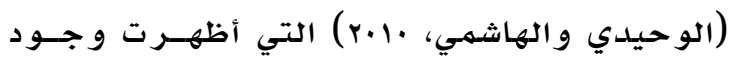

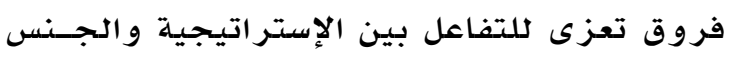
لصالح الطالبات. التو صيات و المقتر حات في ضوء نتائج الدراسلة توصي الباحثة بما يلي:

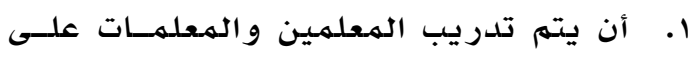
نظرية الذكاءات المتعددة و إسـتر اتيجيات

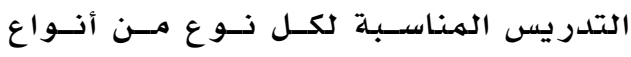
الذكاءات، ووكيفية تشخيص أنواع الذكاء

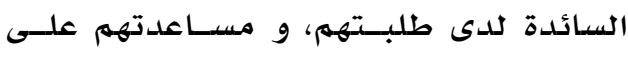
تطوير ذكاءاتهم، بحيث أن يبني المعلمـون

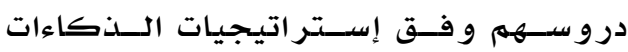
المتعددة لتحقيق التعلم ذي المعنى. r. توصي الدراسلة مصمـمي المنــاهج مـراعـاة

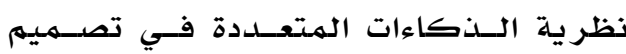

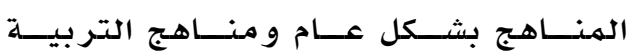
الإسلامية بشكل خاص، مـع الأخذ بالاعتبار

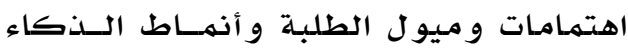

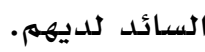


Armstrong, T. (2000). Multiple Intelligences in the Classroom, (2nd ed). Alexandria, VA: Association for Supervision and Curriculum Development.

Armstrong, T. (1994). Multiple Intelligences: Seven Ways To Approach Curriculum, Educational Leadership.

Bilgin, E. K. (2006). The Effect Of Multiple Intelligences Based Instruction On Ninth Grades Chemistry Achievement And Attitudes Toward Chemistry. Unpublished master thesis. Middle East Technical University. Ankara.

Davis, L. (2004). Using the Theory of Multiple Intelligences to Increase the Fourth Grade Student's Academic Achievement in Science. unpublished PhD Dissertation. Nova Southeastern University, USA.

Gardener, H. (1998). Intelligence in seven steps. Retrived on march, 12, 2007, http:/ / www.newhorizons.org/cruft_gard ner.html.

Hernández, J. G. \& Noruzi , M. R. \& Sariolghalam, N. (2010) Multiple Intelligences and the Future of Education in Mexico, Asian Social Science. 6.(6), 139148.

Hoerr, T. R. (2000). Becoming a Multiple Intelligence School. Retrieved March,12,2007,http://www.ascd.org/por tal/site/ascd/template.chapter/menuite m.b71d101a2f7c208cdeb3ffdb62108a0c/?c hapterMgmtld=589c8aec2ecaff00VgnVCM 1000003d01a8c0RCRD.

Hoerr, R., T., (2002). Applying MI In Schools, Retrieved April, 27, 2007, http:/ / www.newhorizons.org/etrategies / mi/Hoerr 2.html.

Kuramı, Ç., Z. \& Eğitim, T., \& Düzeyi, E. (2010) Effects Of Multiple Intelligences Approach In English Classess On Students' Academic Achievement Levels And Attitudes Towards Lesson, e-Journal of New World Sciences Academy, Education Sciences, 1C0138, 5, (2), 411-430.

McCkenzie, W., (2000). Multiple Intelligence's Survey. Retrieved from: April, 15, 2007, www.surfaquarium.common/Mlinvent.ht ml. Pociask, B. A. \& Settles, B. J., (2007). Increasing Student Achievement Through
Brain-Based Strategies. Unpublished PhD Dissertation. Saint Xavier University, Chicago, USA.

Şahin, A., Öngören, H. and ve Çokadar, H., (2010) Effect Of Instruction Based On Multiple Intelligences Theory On Students' Attitudes Towards Science, e-Journal of New World Sciences Academy Education Sciences, 1C0139, 5, (2), 431-445.

Ucak, E., Bag, H. \& Usak, M., (2006). Enhancing Learning Through Multiple Intelligences in Elementary Science Education. Journal of Baltic Science Education, 2(10): 61-69.

Uysal, E., (2004). The Relationships Between Seventh And Tenth Grade Studen's SelfEstimated Intelligences, And Their Science Or Physics Achievement. unpublished Master Thesis . Middle East Technical University. Ankara 